\title{
Mechanisms of Crack Initiation and Propagation in Dense Linear Multihole Directional Hydraulic Fracturing
}

\author{
Jiangwei Liu, ${ }^{1,2}$ Changyou Liu $\mathbb{D}^{1,2}$ and Qiangling Yao $\mathbb{D}^{1,2}$ \\ ${ }^{1}$ State Key Laboratory of Coal Resources and Safe Mining, China University of Mining and Technology, Xuzhou, 221116, China \\ ${ }^{2}$ School of Mines, China University of Mining and Technology, Xuzhou, 221116, China \\ Correspondence should be addressed to Changyou Liu; cyliucumt@163.com
}

Received 23 July 2019; Revised 16 October 2019; Accepted 5 November 2019; Published 7 December 2019

Academic Editor: Mohammad Rafiee

Copyright (c) 2019 Jiangwei Liu et al. This is an open access article distributed under the Creative Commons Attribution License, which permits unrestricted use, distribution, and reproduction in any medium, provided the original work is properly cited.

Artificially fracturing coal-rock mass serves to form break lines therein, which is related to the distribution of cracked boreholes. For this reason, we use physical experiments and numerical simulations to study the crack initiation and propagation characteristics of dense linear multihole drilling of fractured coal-rock mass. The results indicate that only in the area between the first and last boreholes can hydraulic fracturing be controlled by dense linear multihole expansion along the direction of the borehole line; in addition, no directional fracturing occurs outside the drilling section. Upon increasing parameters such as the included angle $\theta$ between the drilling arrangement line and the maximum principal stress $\sigma_{1}$ direction, the drilling spacing $D$, the difference $\Delta \sigma$ in principal stress, etc., the effect of directional fracture is gradually weakened, and the hydraulic fractures reveal three typical cracking modes: cracking along the borehole line, bidirectional cracking (along the borehole line and perpendicular to the minimum principal stress $\sigma_{3}$ ), and cracking perpendicular to $\sigma_{3}$. Five propagation modes also appear in sequence: propagating along borehole line, steplike propagation, S-shaped propagation, bidirectional propagation (along the borehole line and perpendicular to $\sigma_{3}$ ), and propagation perpendicular to $\sigma_{3}$. Based on these results, we report the typical characteristics of three-dimensional crack propagation and discuss the influence of the gradient of pore water pressure. The results show clearly that crack initiation and propagation are affected by both the geostress field and the pore water pressure. The pore water pressure will exhibit a circular-local contact-to-integral process during crack initiation and expansion. When multiple cracks approach, the superposition of pore water pressure at the tip of the two cracks increases the damage to the coal rock, which causes crack reorientation and intersection.

\section{Introduction}

Coal mining often encounters technical problems such as hard roofs, hard thick top coal, rock bursts, coal and gas outburst, etc. Hydraulic fracturing technology can transform coal-rock mass, form fracture lines in hard coal-rock mass, improve the permeability of coal seams $[1,2]$, control hard roofs [3-11], and improve top-coal caving [12]. To direct the propagation of hydraulic cracks, the stress field of the coalrock mass must be oriented so that the effective tensile stress in the specified direction preferentially reaches the critical condition, forming a dominant fracture plane $[13,14]$. The formation of fracture lines is related to the distribution of boreholes, including borehole spacing and arrangement. A multi-borehole single-row arrangement can reduce the effect of staggered borehole distance on the formation of fracture line and is an effective means to control the direction in which coal-rock fractures. Such an approach not only cuts off hardtop coal and the roof of a working face in the vertical direction, reduces the probability of rock burst, increases topcoal recovery, and enhances gas permeability but also cuts the roof off of pillarless roadways in certain directions to relieve pressure while retaining the roadway [15].

At present, directional hydraulic fracturing controlled by dense linear multihole drilling is used mainly to improve the directionality of hydraulic fracturing of radial perforations, enhance the penetration of cracks, and increase the production of petroleum [16-18] and coalbed methane $[19,20]$. Previous studies have investigated how pilot boreholes affect crack propagation in hydraulic fracturing [21] and the spatial stress field of crack propagation guided by multiboreholes [22, 23]. Dong et al. [24, 25] established a 
theoretical model based on linear elastic fracture mechanics and calculated the stress intensity factors of two symmetric radial cracks in a pressurized borehole, based on which they proposed a maximum tangential strain criterion for studying fracture propagation in hydraulic fracturing. Guo et al. [26] established a mechanical model of two radial boreholes (basic research units) and derived the directional cracking criteria for multiradial boreholes based on plastic-zone theory [27]. However, these studies did not consider how the field of pore water pressure affects hydraulics-induced crack propagation. Coal-rock mass is a permeable multi-borehole medium, so multi-borehole single-row coupled hydraulic fracturing causes high-pressure water to seep into the coalrock mass surrounding the boreholes and thereby increases the pore water pressure [28-30], forming multiple osmotic water pressure fields and pore water pressure gradients, which can strongly influence crack propagation in hydraulic fracturing [31, 32]. Zhao and Huang [32] proposed a method of directional hydraulic fracturing controlled by dense linear multihole drilling and studied experimentally how the three different pumping modes affect the initiation and propagation of hydraulic fractures between boreholes. On this basis, the influence of three main factors including borehole spacing, angle $\theta$ between borehole direction and $\sigma_{1}$, and the principal stress difference on fracture propagation law of dense linear multihole drilling controlled directional hydraulic fracturing is studied in this paper.

Because directional hydraulic fracturing controlled by dense linear multihole drilling is not widely applied in coal mines, the behavior and mechanism of crack propagation are also less known. To redress this situation, this paper analyzes the crack initiation and propagation in directional hydraulic fracturing controlled by dense linear multihole drilling based on the effect of pore water pressure gradient. A model of typical crack initiation and propagation is analyzed, thereby providing a robust theoretical basis for application in the field.

\section{Principle of Directional Hydraulic Fracturing Controlled by Dense Linear Multihole Drilling}

Figure 1 shows the mechanism and process of directional hydraulic fracturing controlled by dense linear multihole drilling. The three major stresses involved are $\sigma_{1}, \sigma_{2}$, and $\sigma_{3}$, with $\sigma_{1}$ being the maximum principal stress, $\sigma_{2}$ being the intermediate principal stress, $\sigma_{3}$ being the minimum principal stresses, and $\sigma_{1}>\sigma_{2}>\sigma_{3}$. Figure 1 (a) shows the crackpropagation mechanism of single-hole hydraulic fracturing. The results show that after the high-pressure water enters fracture $\mathrm{A}$, the water pressure $\mathrm{P} 1$ is generated at the tip end and penetrates into the front pore to increase the pore water pressure P0. When the water pressure P1 and the pore water pressure $\mathrm{P} 0$ together overcome the minimum principal stress $\sigma_{3}$ and the tensile strength of the rock, the hydraulic fractures will expand perpendicular to the minimum principal stress. Figure 1(b) shows the mechanism by which dense linear multiholes are used to control the propagation direction of hydraulic fracturing, where high-pressure water enters fracture A (B) and generates water pressure P1 (P2) at the tip of the fracture. Since the water pressures of fractures $A$ and $B$ are superimposed on each other, tensile stress will be generated perpendicular to the direction of the borehole line. Upon increasing the water-injection pressure, the tensile stress increases rapidly. When it exceeds the sum of the compressive stress in this direction and the tensile strength of the rock, the hydraulic crack will crack and expand along the borehole line. Figure 1 shows the process of multihole single-row coupled directional hydraulic fracturing. A row of drill holes is prearranged in the specified direction, and the drill holes are parallel to each other. Next, multiple drill holes (usually 3 6) are simultaneously injected with a significant quantity of water by using a high-pressure pump to break the coal-rock mass along the borehole line. This technique controls the fracture direction of the coalrock mass.

Such an approach not only cuts off hard-top coal and the roof of a working face in the vertical direction, reduces the probability of rock burst, increases top-coal recovery, and enhances gas permeability but also cuts the roof off of pillarless roadways in certain directions to relieve pressure while retaining the roadway.

\section{Directional Hydraulic Fracturing Controlled by Dense Linear Multihole Drilling: Experiment}

Based on the previous study [32], the fracture initiation and propagation laws of dense linear multihole drilling controlled directional hydraulic fracturing under the influence of different factors were studied by physical experiments.

3.1. Experimental System. The $4000 \mathrm{kN}$ true triaxial hydraulic fracturing experiment system is employed (Figure 2). This system consists of a trial table, loading system, and monitoring system. The triaxial confining loading which can reach $4000 \mathrm{kN}$ on the cubic specimens, which vary in sizes of $300 \times 300 \times 300 \mathrm{~mm}^{3}$ and $500 \times 500 \times 500 \mathrm{~mm}^{3}$, is realized through 6 flat jacks to produce the circumstances of crustal stress.

The compressive pressure and hydraulic pressure can be controlled by the 4-channel electrohydraulic servo controlling system with high precision satisfying the experimental requirement. 3 channels are assigned to produce compressive pressure. Every hole is injected with water by the corresponding oil cylinder with the oil and water conversion supercharger. $63 \mathrm{MPa}$ is the top limit of hydraulic pressure applied to the boreholes. During the experiment, the plot of triaxial compressive pressure and hydraulic pressure can be visualized and recorded on the software screen.

3.2. Experimental Method. The specimens are made of the No. 32.5 cement and filtered fine sand with the matching ratio of $3.5: 1: 0.3$ (sand: cement: water). The specific parameters about specimens are shown in Table 1. 

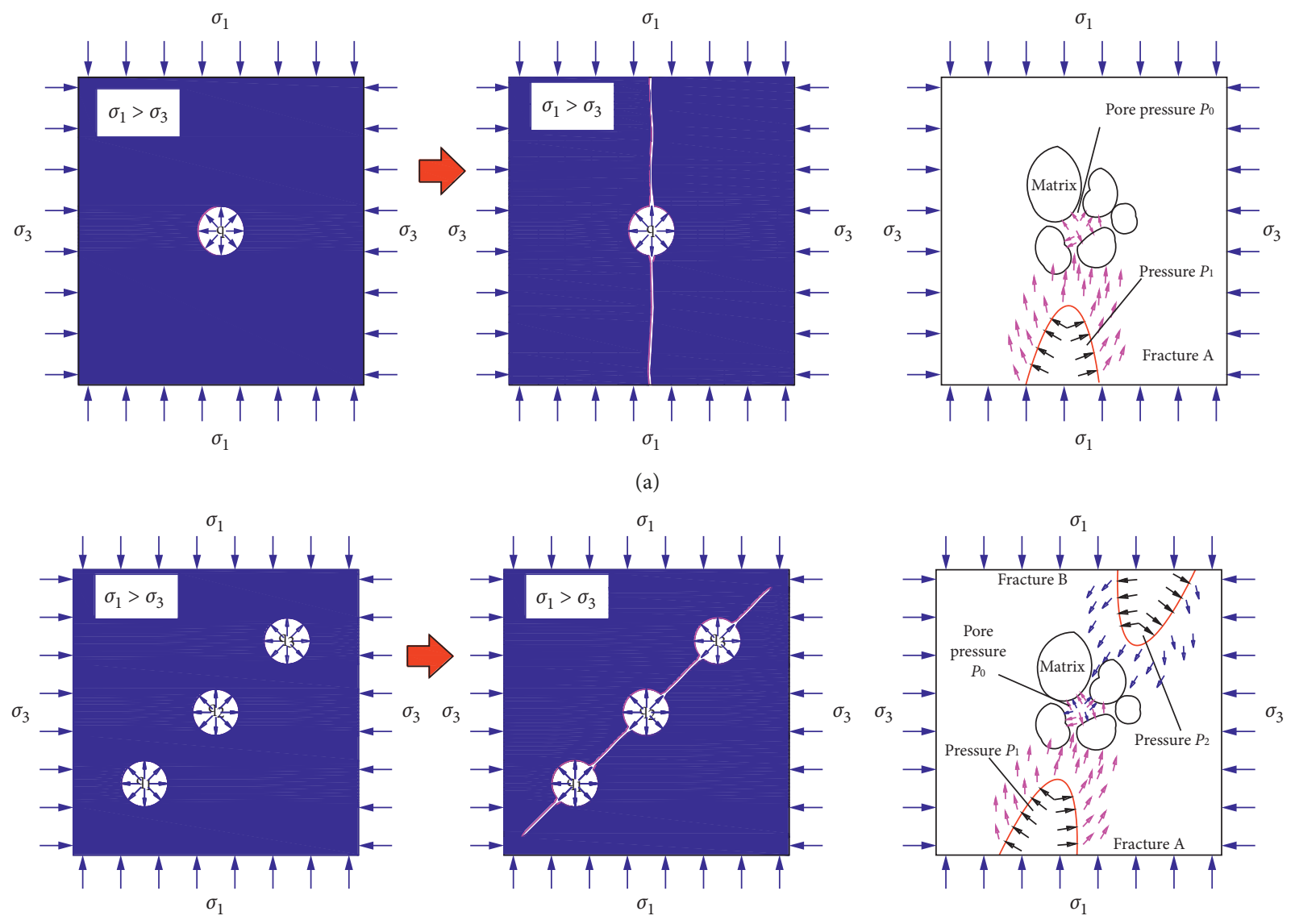

(b)

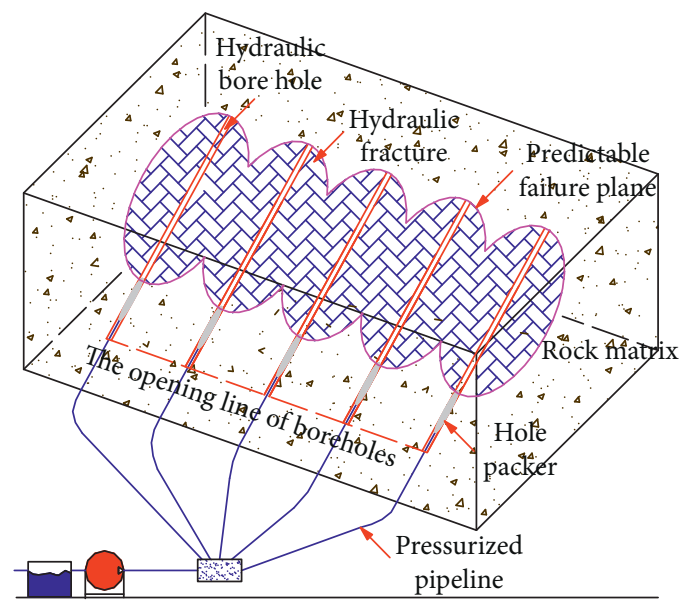

Tank Water Shunt

pump

(c)

FIgURe 1: Principle and technology of directional hydraulic fracturing controlled by dense linear multihole drilling. (a) Traditional principle of directional hydraulic fracturing. (b) Principle of directional hydraulic fracturing controlled by dense linear multihole drilling. (c) Technology of directional hydraulic fracturing controlled by dense linear multihole drilling.

In this experiment, the cubic specimen of $500 \times 500 \times 500 \mathrm{~mm}^{3}$ is simulated as the real coal and rock matrix. The hole packer, which is $18 \mathrm{~mm}$ in outer radius, $8 \mathrm{~mm}$ in inner radius, and $220 \mathrm{~mm}$ in length, is sealed with the specimens by integrated pouring to ensure the tightness.
And there is a $100 \mathrm{~mm}$ length naked hole extending from the end of the hole packer. This section of naked hole is spared to simulate the true situation of hydraulic fracturing. In one specimen, 2 or 3 linear layout boreholes can be installed. Limited by the production equipment of the cubic specimen, 


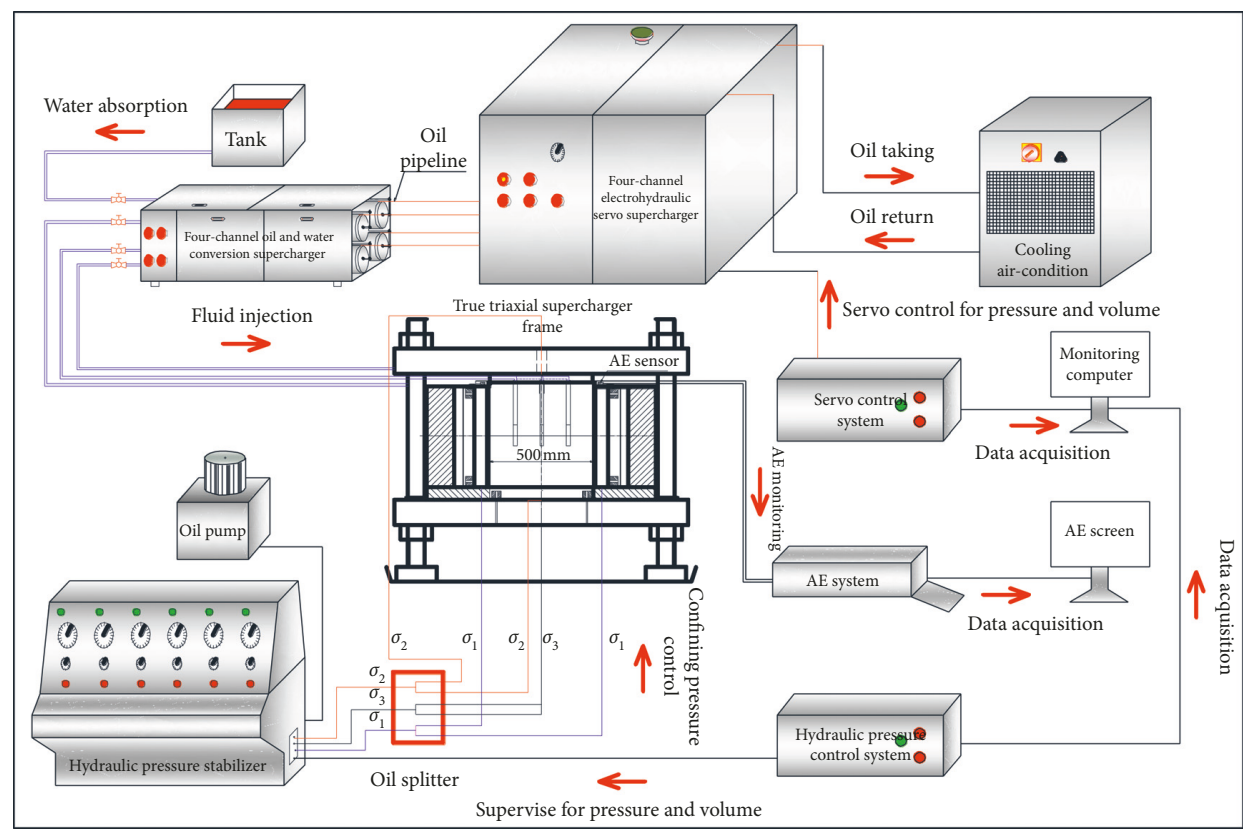

(a)

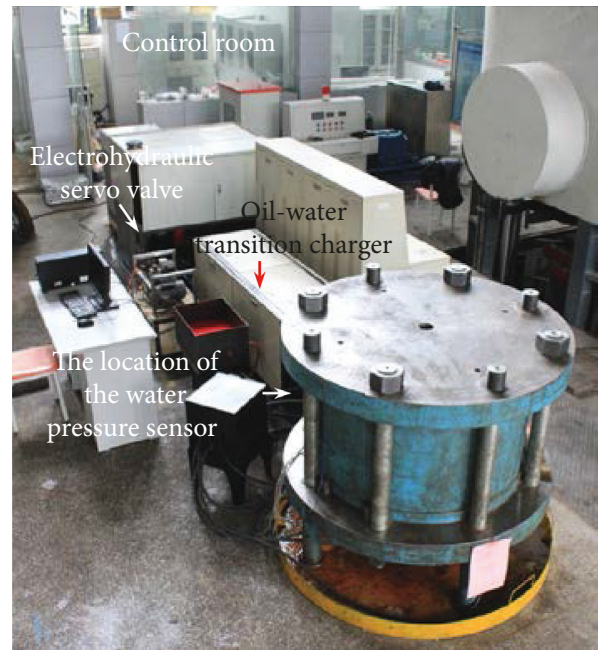

(b)

FIgURe 2: The true triaxial hydraulic fracturing experiment system. (a) Block diagram. (b) Physical photo.

TABle 1: Physical and mechanical parameters of the cement mortar.

\begin{tabular}{lcccc}
\hline $\begin{array}{l}\text { Porosity } \\
\phi(\%)\end{array}$ & $\begin{array}{c}\text { Permeability } \\
K(\mathrm{mD})\end{array}$ & $\begin{array}{c}\text { Uniaxial compressive } \\
\text { strength } \\
\sigma_{c}(\mathrm{MPa})\end{array}$ & $\begin{array}{c}\text { Modulus of } \\
\text { elasticity } E(\mathrm{GPa})\end{array}$ & $\begin{array}{c}\text { Fracture } \\
\text { toughness } \\
K_{1 c}\left(\mathrm{~N} \cdot \mathrm{mm}^{3 / 2}\right)\end{array}$ \\
\hline 12.7885 & 1.1339 & 6.2747 & 0.7208 & 13.2300 \\
\hline
\end{tabular}

only two types of specimens containing multiple waterinjection holes can be produced at present. One is a specimen with two water-injection holes and is used in the experiment of synchronous water injection into two boreholes, and the other is a specimen with three waterinjection holes and is used for the experiment of synchronous water injection into three boreholes (Figure 3(a)). The angle shown in Figure 3(b) between hole's layout and direction of $\sigma_{1}$ is 15 degrees two holes with $282 \mathrm{~mm}$ interval and $114 \mathrm{~mm}$ away from the edge of the sample are installed (Figure 3(b)). All the distances exceed 5 times the diameters of all holes to eliminate the local stress concentration. The specimens are made in a specialized mold, which needs to be dismantled three days later and restrained with stoppers so that the working accuracy and the location of prefabricated holes can be guaranteed. After 28 days' maintenance, they can be used in an experiment. 


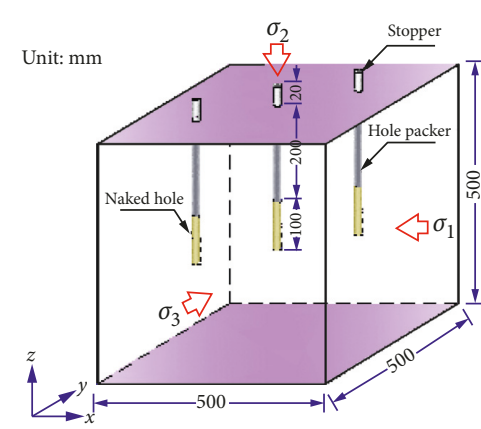

(a)

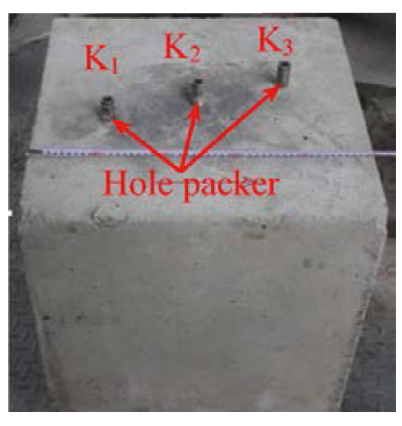

(b)

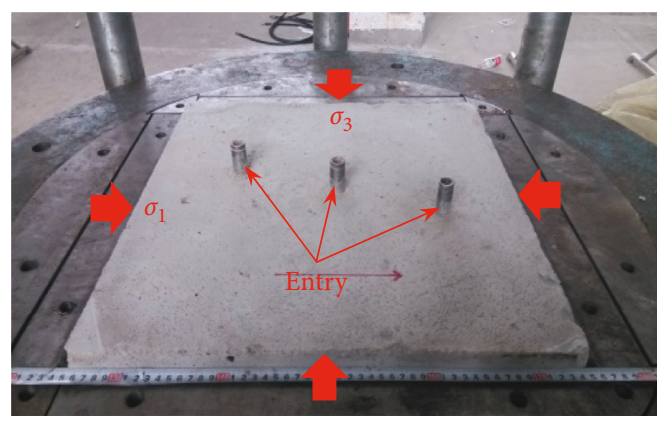

(c)

Figure 3: The manufacture of specimens and loading $\left(\sigma_{1}>\sigma_{2}>\sigma_{3}\right)$. (a) Cubic mode. (b) The shape of the specimen. (c) Place in the loading frame.

On the one hand, in situ stress conditions are intricate and the changes in crustal stress have a considerable impact on the extension of hydraulic fractures. On the other hand, the adaption in the holes' space is usually an effective way to alternate the shape of fractures. So, the crustal distribution and the holes' space are considered to find the typical propagation behavior of hydraulic cracks controlled by dense linear multiholes (Table 2).

With specimen put into the loading frame shown in Figure 3(c), the compressive pressure is output and held for more than $5 \mathrm{~min}$ and the true triaxial stress environment is realized. Then, water is pumped to fracture the specimen. The experimental system can quantitatively control the water inlet flow rate of each borehole with a flow range of $0-500 \mathrm{ml} / \mathrm{min}$. To simulate the process of large-flow water injection on-site, the water inlet flow rate of each borehole is set at $500 \mathrm{ml} / \mathrm{min}$ to implement simultaneous water injection with an equal flow rate of porous water. In addition, the water is colored in red to make the trace of fractures visible. When water seeps outside the loading frame, the experiment ceases.

3.3. Water Pressure during Hydraulic Fracturing. Figure 4 shows the water pressure during hydraulic fracturing. The water pressure curve of the samples basically consists of four stages. For sample $X(X=\mathrm{A}, \mathrm{B}, \mathrm{C}), \mathrm{O}-\mathrm{X}_{1}$ is the water-injection and pressure-increase stage, $\mathrm{X}_{1}-\mathrm{X}_{2}$ is the crack-initiation stage, $\mathrm{X}_{2}-\mathrm{X}_{3}$ is the stable expansion stage, and $\mathrm{X}_{3}-\mathrm{X}_{4}$ is the pressure-relief stage. In the crack-initiation stage, the first rupture occurred in the sample, and the water pressure dropped suddenly. During the steady expansion stage, the water pressure fluctuated continuously. This result is attributed to the high-pressure water that entered after the hydraulic crack opened, causing the crack to expand. The expansion of the crack reduces the water pressure. Once water-injection ceases, the water pressure decreases.

Comparing test block A and test block B, the water pressure required for cracking of test block $\mathrm{B}$ is lower than that of test block A. It can be seen that the lower the minimum principal stress $\sigma_{3}$ is, the lower the water pressure required to crack the test block. Comparing specimen $B$ with specimen $C$ shows that the water pressure required to crack specimen $\mathrm{C}$ is greater than that for specimen B. It can be seen that the larger the distance of the drilled holes is, the larger the water pressure required for the cracking of the test block.

\subsection{Controlling Propagation Shape of Directional Hydraulic Fracturing by Dense Linear Multihole Drilling}

3.4.1. Absolute Initial Cracking along the Ligature of Holes. With holes marked with $K_{1}, K_{2}$, and $K_{3}$ from left to right, the fractured specimen $\mathrm{A}$, in the stress environment where $\sigma_{1}$ is $6 \mathrm{MPa}, \sigma_{2}$ is $5 \mathrm{MPa}$, and $\sigma_{3}$ is $4 \mathrm{MPa}$, is demonstrated in Figure 5(a). The fractured section of $\mathrm{K}_{1}-\mathrm{K}_{3}$ basically begins and goes along the direction of ligature of the holes, which is apparently directional. Outside the fractured section of $\mathrm{K}_{1}-\mathrm{K}_{3}$, fractures begin and go along the direction of $\sigma_{1}$. All the holes lie in the smooth hydraulic failure plane which is orientational and not biforked or layered.

The distinct directional behavior within the section $\mathrm{K}_{1}-\mathrm{K}_{3}$ results from the high level of stress concentration induced by the superposition of stress between two holes. This stress concentration provides a priority to the tensile strength of samples, finally cracking initially along the ligature of holes. As the pressurized water increases, the fractures are forced to open to going closer to each other and consequently intersecting smoothly. Outside the stretch of $\mathrm{K}_{1}-\mathrm{K}_{3}$, the failure plane almost perpendicular to the minimum principal stress has an undesirable directional effect because the area of stress superimposition between holes has very limited impact on the fractures as they move away where the stress field dominates the propagation. All these factors demonstrate that good directional effect is often obtained within the span of different boreholes. The results show that only in the area between the first and last boreholes can the hydraulic cracks expand along the direction of the borehole line, causing the coalrock mass to fracture along the borehole line and thereby causing directional fracture. In areas outside the drilling section, the hydraulic fracturing is mainly perpendicular to the minimum principal stress expansion and no directional fracturing occurs.

3.4.2. The Crack Initiations along the Ligature of Holes or Perpendicular to the Minimum Principal Stress. In specimen 
TABLe 2: Experimental scheme.

\begin{tabular}{lccc}
\hline No. & Principal stress $(\mathrm{MPa})$ & Borehole spacing $D(\mathrm{~mm})$ & Arrangement angle of boreholes $\theta(\mathrm{deg})$ \\
\hline A & $\sigma_{1}=6, \sigma_{2}=5, \sigma_{3}=4$ & 141 & 15 \\
B & $\sigma_{1}=6, \sigma_{2}=5, \sigma_{3}=2$ & 141 & 15 \\
C & $\sigma_{1}=6, \sigma_{2}=5, \sigma_{3}=2$ & 282 & 15 \\
\hline
\end{tabular}

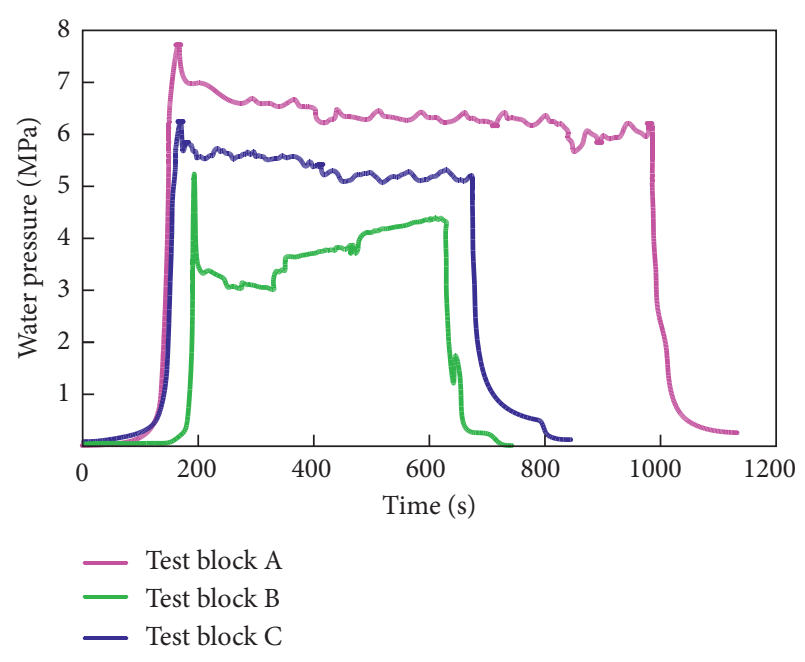

FIgURE 4: Water pressure during hydraulic fracturing.

B $\left(\sigma_{1}=6 \mathrm{MPa}, \sigma_{2}=5 \mathrm{MPa}\right.$, and $\left.\sigma_{3}=2 \mathrm{MPa}\right), \mathrm{K}_{1}$ and $\mathrm{K}_{2}$ mainly crack along the $\sigma_{1}$ direction, and the water pressure in the crack of the $\mathrm{K}_{2}$ borehole expands along the $\sigma_{1}$ direction. Conversely, the branch cracks are connected to the hydraulic cracks of the $K_{1}$ and $K_{3}$ boreholes; in other words, the $\mathrm{K}_{2}$ borehole, which is in the middle, extends along both the $\sigma_{1}$ direction and along the line connecting the boreholes. Moreover, on both sides, the range of expansion of the hydraulic cracks $K_{1}$ and $K_{3}$ is relatively small, and the undulation of the crack surface is relatively large, where the central hydraulic crack of $\mathrm{K}_{2}$ basically penetrates the entire surface of the sample. The expansion range is large and the crack surface is relatively flat (Figure 5(b)). This result shows that the expansion of the hydraulic fracture in the middle borehole is more advantageous than that in the borehole on both sides, which is mainly explained by the superposition of the pore water pressure generated by the boreholes on both sides of the intermediate borehole.

3.4.3. Cracking Initiation Precisely Perpendicular to Minimal Principal Stress. Compared with specimen B whose boreholes' space is $141 \mathrm{~mm}$, in specimen C whose boreholes' space is $282 \mathrm{~mm}$ and loading condition is the same as specimen $B$, the fractures of $K_{1}$ and $K_{2}$ begin and continue, respectively, along the $\sigma_{1}$ and are smooth and paralleled as shown in Figure 5(c). This is because the large distance between holes weakens the stress concentration in these regions. And the propagation of hydraulic fractures is mainly influenced by the in situ stress.

\section{Crack Initiation and Propagation of Directional Hydraulic Fracturing Controlled by Dense Linear Multihole Drilling}

4.1. Numerical Simulation. To study the crack initiation and propagation of directional hydraulic fracturing controlled by dense linear multihole drilling, we used RFPA $^{2 \mathrm{D}}$-flow to simulate the hydraulic fracturing controlled by dense linear multihole drilling under different conditions. RFPA $^{2 \mathrm{D}}$-flow is a real fracture process analysis system with the elastic mechanics as the stress analysis tool and elastic damage theory and its modified failure criterion as the medium deformation and failure analysis module [30]. The basic idea is the rock structure is uniform and its mesoscopic damage element parameters follow a certain probability distribution (Weibull). So, the relationships between the media mechanical properties of the microscopic view and that of the macroscopic view were established. The mesoscopic element in the rock is brittle and in the nature of the residual strength. Its mechanical behavior can be described by the elastic damage theory. The maximum tensile strain criterion and the Mohr-Coulomb criterion are set as the damage thresholds. The seepage process in rock meets the Biot consolidation theory and the modified Terzaghi effective stress principle. The relationship between the permeability and the stress-strain function can be satisfied under the elastic state of the microelement. The permeability increases after the fracture damage. Therefore, the software can be used to solve the problem of the basic seepage characteristics and the solid-liquid coupling of rock mass, which is very suitable for the hydraulic fracturing problems.

The basic equations involved in the software are as follows:

Constitutive equation:

$$
\sigma_{i j}^{\prime}=\sigma_{i j}-\alpha p \delta_{i j}=\lambda \delta_{i j} \varepsilon_{v}+2 G \varepsilon_{i j}
$$

Seepage equation:

$$
k \nabla^{2} p=\frac{1}{Q}-\frac{\partial p}{\partial t}-\alpha \frac{\partial \varepsilon_{v}}{\partial t}
$$

Seepage-stress relationship equation:

$$
k(\sigma, p)=\xi k_{0} e^{-\beta\left(\sigma_{i j} \beta-\alpha p\right)},
$$

where $\sigma_{i j}$ and $\sigma_{i j}^{\prime}$ are, respectively, the total stress and the effective stress; $\varepsilon_{i j}$ and $\varepsilon_{v}$ are, respectively, the total strain and the volumetric strain; $\delta$ is the Kronecker constant; $G$ and $\lambda$ 

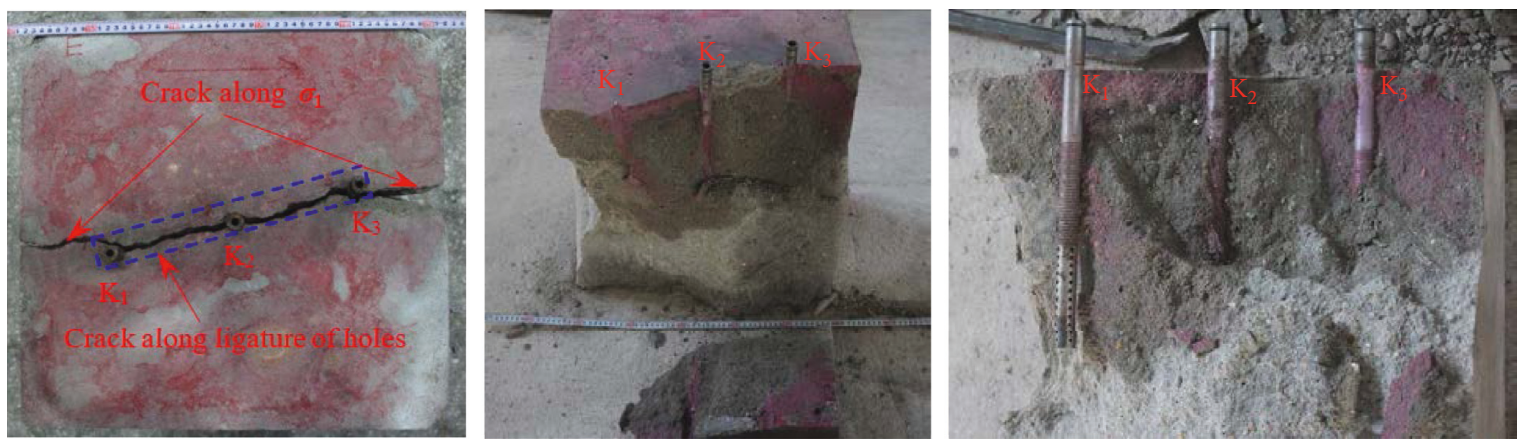

(a)

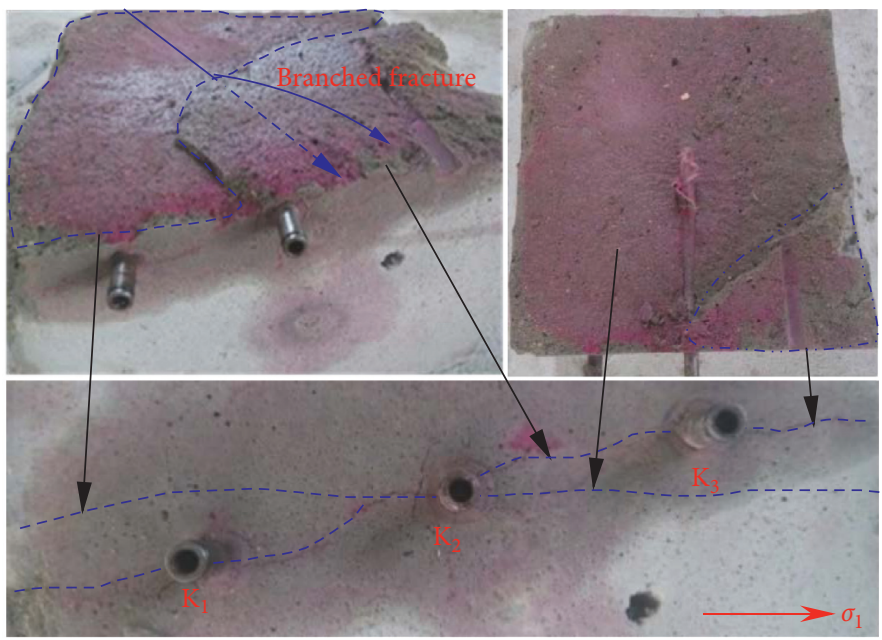

(b)

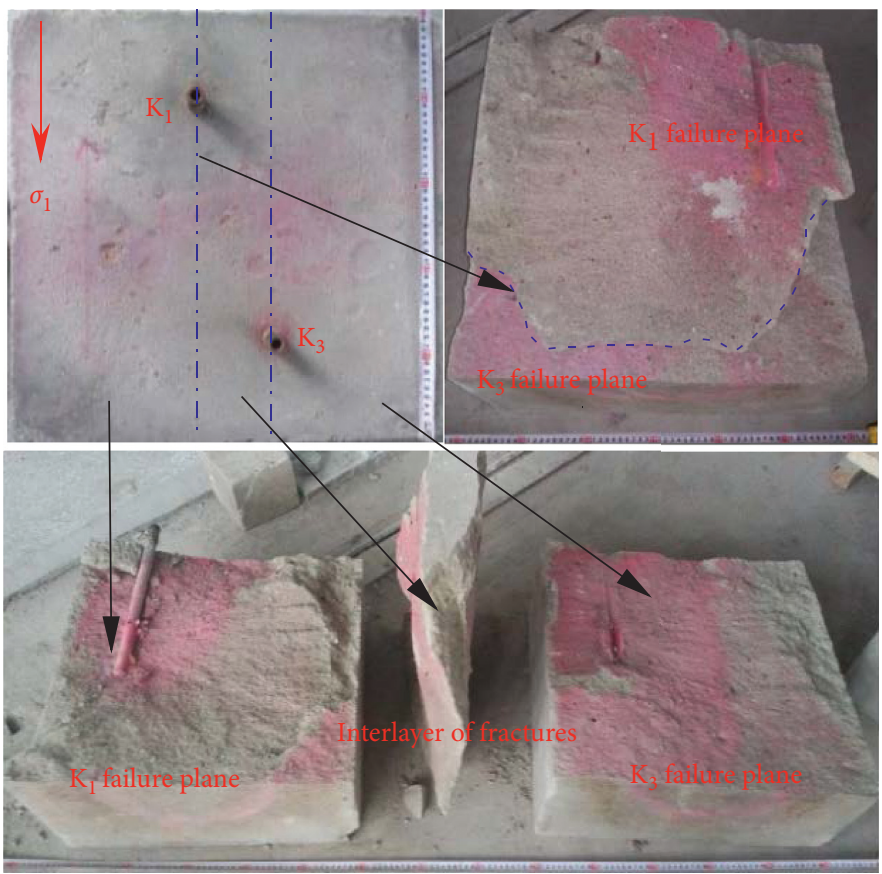

(c)

Figure 5: Crack propagation of directional hydraulic fracturing controlled by dense linear multihole drilling. (a) Crack along ligature of holes (specimen A). (b) Hydraulic cracks along ligature of holes and $\sigma_{1}$ (specimen B). (c) Hydraulic cracks totally along $\sigma_{1}$ (specimen C). 
are, respectively, the shear modulus and the Lame constant; $k$ is the permeability coefficient; $p$ is the pore water pressure; $Q$ is the Biot constant, describing the change of water capacity caused by the water pressure; $\beta$ is the coupling coefficient; $\alpha$ is the pore water pressure coefficient; and $\xi$ is the jump coefficient of permeability; when the stress of the unit reaches Mohr-Coulomb or the strength of extension, the permeability coefficient increases sharply according to formula (3).

The numerical model is shown in Figure 6. The model size is $2000 \mathrm{~mm} \times 2000 \mathrm{~mm}$ and is divided into $200 \times 200$ units. The material is heterogeneous, and the specific material parameters of the model are given in Table 3. The model has three boreholes labeled $K_{1}, K_{2}$, and $K_{3}$. The borehole diameter $d=40 \mathrm{~mm}$, and the borehole spacing is $D$. The arrangement angle of boreholes between borehole direction and $\sigma_{1}$ is $\theta$. The confining pressures $\sigma_{1}$ and $\sigma_{3}$ $\left(\sigma_{1}>\sigma_{3}\right)$ are applied around the model. Water pressure is applied simultaneously to the three boreholes. The water pressure starts at zero and increases in steps of $1 \mathrm{MPa}$ until destruction.

To study the crack initiation and propagation of directional hydraulic fracturing controlled by dense linear multihole drilling under the effect of various parameters, we use the parameter sets given in Table 4 in the numerical simulation. A total of 15 simulations of were made, which were separated into three groups: simulations A1-A5 involved variations in arrangement angle of boreholes $\theta$, simulations B1-B5 involved variations in borehole spacing $D$, where $d$ is the borehole diameter, and simulations $\mathrm{C} 1-\mathrm{C} 5$ involved variations in the principal stress difference $\Delta \sigma$, where $\Delta \sigma=\left(\sigma_{1}-\sigma_{3}\right)$.

\subsection{Characteristics of Crack Initiation in Hydraulic} Fracturing. Figure 7(a) compares simulations A1-A5 to see how the arrangement angle of boreholes $\theta$ affects hydrauliccrack initiation in hydraulic fracturing. When $\theta=15^{\circ}$, cracks initiate in the direction of the borehole line; when $\theta=30^{\circ}$, the cracks within the borehole section initiate along the borehole line, and the cracks outside of the borehole section initiate perpendicular to $\sigma_{3}$; when $\theta=45^{\circ}$, the cracks within the borehole section begin to branch, some cracks initiate along the borehole line, and some cracks initiate perpendicular to $\sigma_{3}$; when $\theta=60^{\circ}$ or $75^{\circ}$, the cracks basically initiate perpendicular to $\sigma_{3}$.

Figure 7(b) compares simulations B1-B5 to see how borehole spacing $D$ affects hydraulic-crack initiation in hydraulic fracturing. When $D=5 d$, cracks basically initiate along the borehole line; when $D=6 d$, the cracks within the borehole section initiate along the borehole line, and the cracks outside the borehole section initiate perpendicular to $\sigma_{3}$; when $D=7 d$ or $8 d$, some cracks within the borehole section initiate along the borehole line, whereas other cracks within the borehole section initiate perpendicular to $\sigma_{3}$; when $D=9 d$, cracks initiate perpendicular to $\sigma_{3}$.

Figure 7 (c) compares simulations C1-C5 to see how the principal stress difference $\Delta \sigma$ affects hydraulic-crack initiation in hydraulic fracturing. When $\Delta \sigma=1 \mathrm{MPa}$, cracks

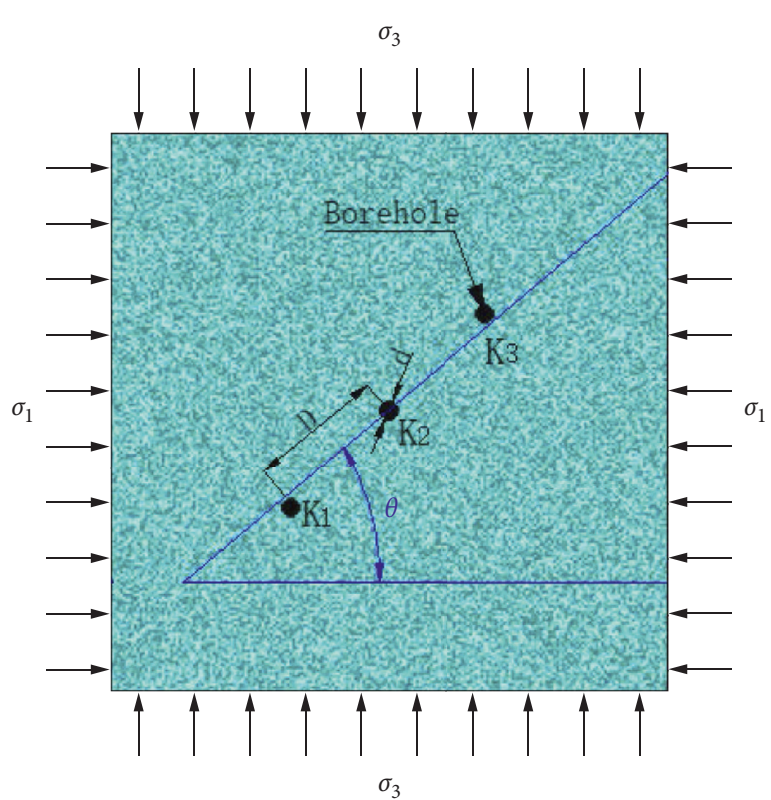

FIgURE 6: Numerical model.

TABLE 3: Material parameters of the model.

\begin{tabular}{lc}
\hline Mechanics and seepage parameter & Rock stratum \\
\hline Homogeneous degree & 4 \\
Mean of compressive strength $\sigma_{0}(\mathrm{MPa})$ & 75 \\
Mean of elastic modulus $E_{0}(\mathrm{GPa})$ & 30 \\
Poisson ratio $\mu$ & 0.25 \\
Internal friction angle $\varphi\left(^{\circ}\right)$ & 30 \\
Pressure-tension ratio & 10 \\
Porosity ratio & 0.1 \\
Seepage coefficient $K(\mathrm{~m} / \mathrm{d})$ & 0.01 \\
Pore water pressure $(\mathrm{MPa})$ & 0.1 \\
Coupling coefficient & 0.1 \\
Damage mutation coefficient & 5 \\
\hline
\end{tabular}

basically initiate along the borehole line; when $\Delta \sigma=3 \mathrm{MPa}$, some cracks initiate along the borehole line, whereas other cracks initiate perpendicular to $\sigma_{3}$; when $\Delta \sigma>5 \mathrm{MPa}$, cracks initiate perpendicular to $\sigma_{3}$.

\subsection{Characteristics of Crack Propagation in Hydraulic} Fracturing. Figure 8(a) compares simulations A1-A5 to explore the relationship between crack propagation in hydraulic fracturing and arrangement angle of boreholes $\theta$. When $\theta=15^{\circ}$, hydraulic cracks mainly initiate linearly along the borehole line, and fewer branch cracks appear. The only branch cracks that initiate perpendicular to $\sigma_{3}$ appear at borehole $\mathrm{K}_{3}$. When $\theta=30^{\circ}$, hydraulic cracks initiate along the borehole line; meanwhile, the number of branch cracks increase, and branch cracks perpendicular to $\sigma_{3}$ appear at boreholes $\mathrm{K}_{1}-\mathrm{K}_{3}$, indicating that hydraulic cracks propagate both along the borehole line and perpendicular to $\sigma_{3}$. When $\theta=45^{\circ}$, after hydraulic cracks initiate, they are strongly deflected toward the direction of the borehole line, causing them to approach and eventually intersect nearby hydraulic 
TABLE 4: Numerical simulation scheme.

\begin{tabular}{lccc}
\hline No. & Principal stress $(\mathrm{MPa})$ & Borehole spacing $D(\mathrm{~mm})$ & Angle $\theta$ between borehole direction and $\sigma_{1 .}\left({ }^{\circ}\right)$ \\
\hline A1 & $\sigma_{1}=11, \sigma_{3}=9$ & 225 & $15^{\circ}$ \\
A2 & $\sigma_{1}=11, \sigma_{3}=9$ & 225 & $30^{\circ}$ \\
A3 & $\sigma_{1}=11, \sigma_{3}=9$ & 225 & $45^{\circ}$ \\
A4 & $\sigma_{1}=11, \sigma_{3}=9$ & 225 & $60^{\circ}$ \\
A5 & $\sigma_{1}=11, \sigma_{3}=9$ & 225 & $75^{\circ}$ \\
B1 & $\sigma_{1}=11, \sigma_{3}=9$ & $200(5 d)$ & $40^{\circ}$ \\
B2 & $\sigma_{1}=11, \sigma_{3}=9$ & $240(6 d)$ & $40^{\circ}$ \\
B3 & $\sigma_{1}=11, \sigma_{3}=9$ & $280(7 d)$ & $40^{\circ}$ \\
B4 & $\sigma_{1}=11, \sigma_{3}=9$ & $320(8 d)$ & $40^{\circ}$ \\
B5 & $\sigma_{1}=11, \sigma_{3}=9$ & $360(9 d)$ & $40^{\circ}$ \\
C1 & $\sigma_{1}=11, \sigma_{3}=10$ & 225 & $40^{\circ}$ \\
C2 & $\sigma_{1}=11, \sigma_{3}=8$ & 225 & $40^{\circ}$ \\
C3 & $\sigma_{1}=11, \sigma_{3}=6$ & 225 & $40^{\circ}$ \\
C4 & $\sigma_{1}=11, \sigma_{3}=4$ & 225 & \\
C5 & $\sigma_{1}=11, \sigma_{3}=2$ & 225 & $40^{\circ}$ \\
\hline
\end{tabular}

cracks, creating a ladder form. When $\theta=60^{\circ}$, after hydraulic cracks initiate, they deflect slightly in the direction of the borehole line and do not intersect with nearby cracks, forming several staggered $\mathrm{S}$-shaped extensions. When $\theta=75^{\circ}$, hydraulic cracks initiate perpendicular to $\sigma_{3}$ and the interactions between cracks are weak so that the cracks propagate independently and in parallel. No obvious branch cracks or reorientation occurs.

Figure 8(b) compares simulations B1-B5 to explore the relationship between the propagation of hydraulic cracks and the borehole spacing $D$. When $D=5 d$, hydraulic cracks mainly initiate linearly along the borehole line and without branch cracks. When $D=6 d$, hydraulic cracks initiate along the borehole line, and the number of branch cracks increases. Cracks initiate perpendicular to $\sigma_{3}$ at boreholes $\mathrm{K}_{1}-\mathrm{K}_{3}$, indicating that the cracks propagate both along the borehole line and perpendicular to $\sigma_{3}$. When $D=7 d$, after cracks initiate, they deflect strongly in the direction of the borehole line, approach, and eventually intersect nearby cracks, forming a ladder structure. When $D=8 d$, after cracks initiate, they deflect slightly in the direction of the borehole line but do not intersect with nearby cracks, thereby forming several staggered S-shaped structures. When $D=9 d$, hydraulic cracks initiate perpendicular to $\sigma_{3}$ and interactions between cracks are weak so that the cracks propagate independently and in parallel. No obvious branch cracks or reorientation occurs.

Figure 8(c) compares simulations C1-C5 to explore the relationship between the propagation of hydraulic cracks and the principal stress difference $\Delta \sigma$. When $\Delta \sigma=1 \mathrm{MPa}$, hydraulic cracks mainly propagate linearly along the borehole line, and fewer branch cracks appear. Only a single branch crack initiates perpendicular to $\sigma_{3}$ at borehole $\mathrm{K}_{2}$. When $\Delta \sigma=3 \mathrm{MPa}$, after hydraulic cracks initiate, they deflect strongly in the direction of the borehole line, approach nearby hydraulic cracks, and eventually intersect, forming a ladder structure. At borehole $\mathrm{K}_{2}$, branch cracks propagate perpendicular to $\sigma_{3}$; when $\Delta \sigma=5 \mathrm{MPa}$, after hydraulic cracks initiate, they deflect to a small extent in the direction of the borehole line and do not intersect with nearby cracks, thereby forming several staggered S-shaped structures. When $\Delta \sigma=7 \mathrm{MPa}$, after cracks initiate, their propagation is slightly deflected, and they tend to form S-shaped cracks. When $\Delta \sigma=9 \mathrm{MPa}$, hydraulic cracks initiate perpendicular to $\sigma_{3}$ and interactions between cracks are weak. They propagate independently and in parallel, and no obvious branch cracks or reorientation occurs.

\subsection{Rupture Water Pressure under the Influence of Different} Factors. The relationship between the water pressure $P_{0}$ required for the fracture in the hydraulic fracturing process and $\theta, \sigma_{3}$, and $D$ is as shown in Figure 9. As the arrangement angle of boreholes $\theta$ increases, $P_{0}$ gradually decreases (Figure 9(a)); as the borehole distance $D$ increases, $P_{0}$ gradually increases (Figure 9(b)); with the increase of the minimum principal stress $\sigma_{3}, P_{0}$ gradually increases (Figure 9(c)). It can be seen that the smaller the bore azimuth angle $\theta$ is, the smaller the drill distance $D$ is, the easier the coal-rock mass is cracked along the drilling line, and the lower the water pressure required for fracturing; the lower the minimum principal stress $\sigma_{3}$ is, the greater the principal stress difference is, the easier the coal-rock mass is cracked in the vertical $\sigma_{1}$ direction, and the lower the water pressure required for fracturing.

4.5. Pore Water Pressure and Evolution of Damage due to Multicrack Propagation. Taking the test block C3 as an example, the pore water pressure evolution of the porous single-row coupled directional hydraulic fracturing is shown in Figure 10(a). To analyze the pore water pressure evolution process, only the pore water in the range of 9$14 \mathrm{MPa}$ is selected. In step 14-1, when three boreholes are simultaneously filled with water, the pore water pressure zone is created around each borehole, and the pore water pressure zone of the intermediate borehole is larger than the pore water pressure zone on both sides; in step 15-7, as the water-injection pressure increases, the crack begins to expand, and the pore water pressure zone of the two 

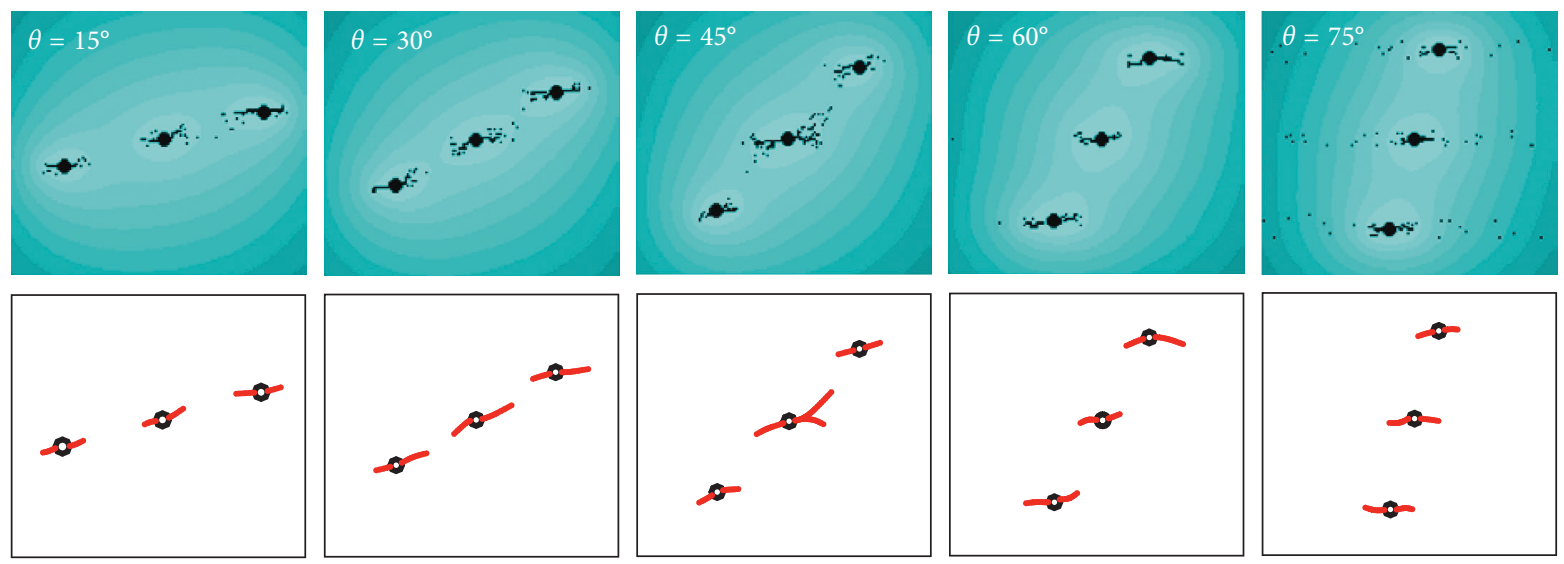

(a)
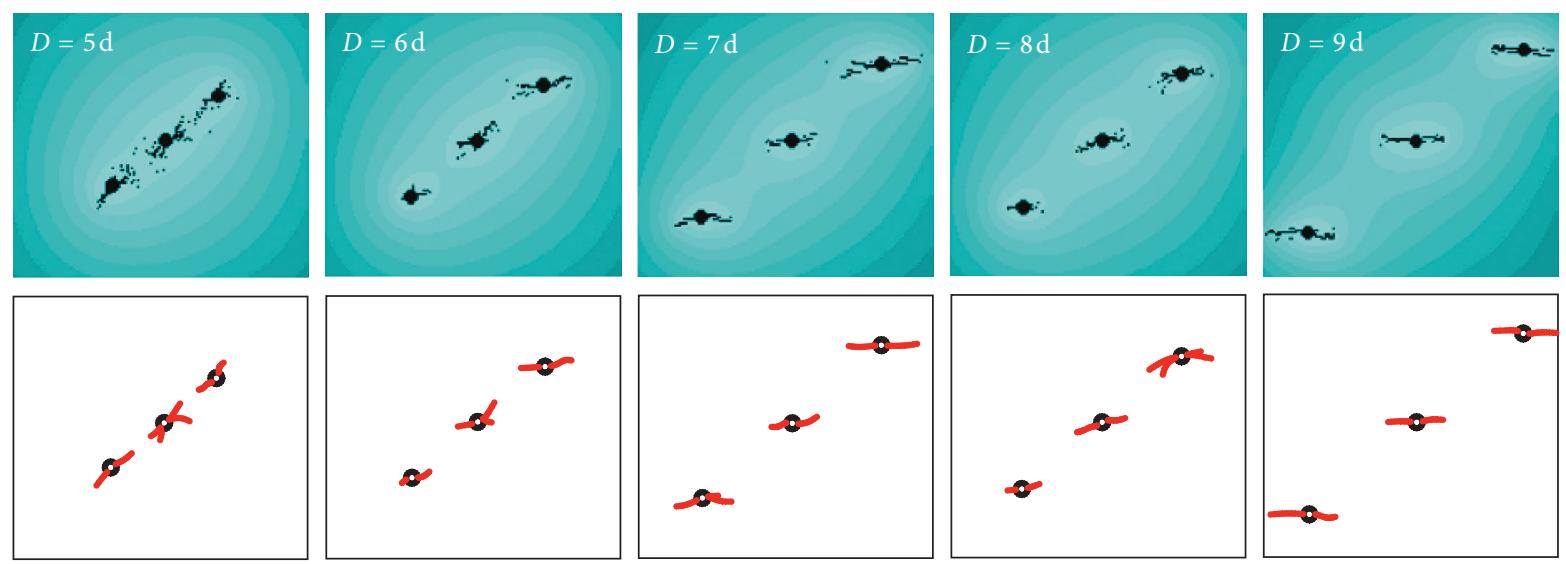

(b)
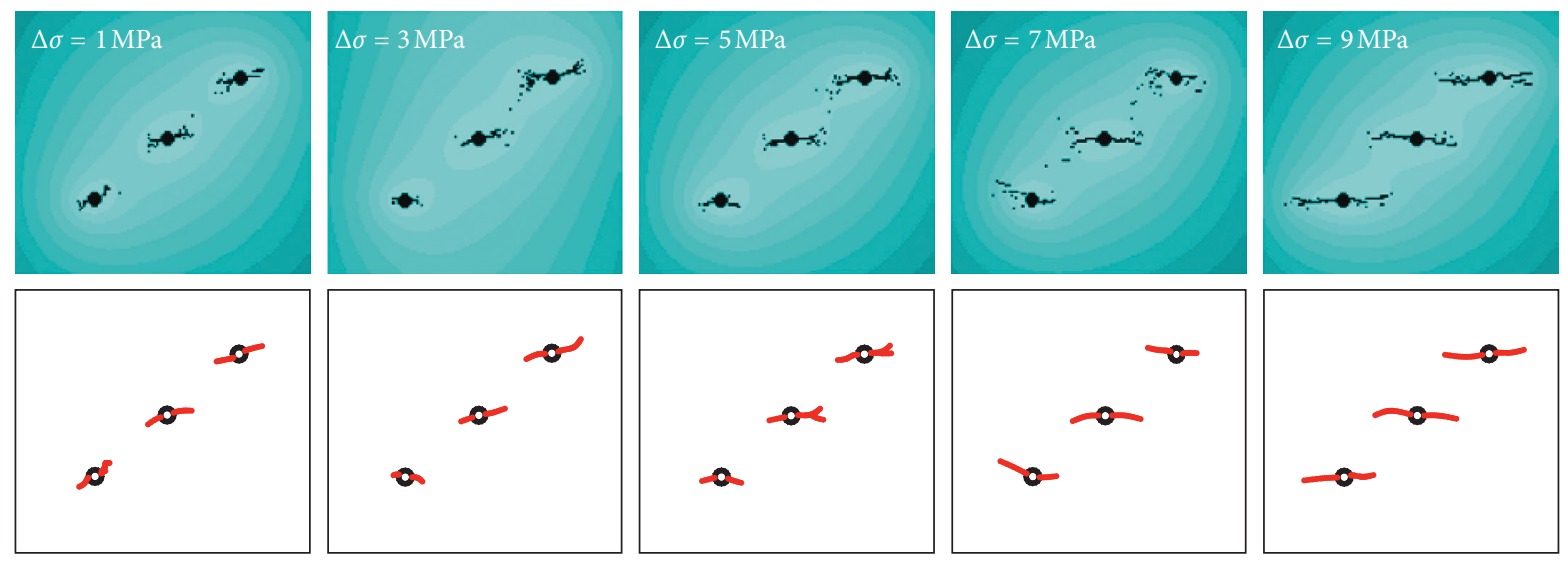

(c)

FIGURE 7: Crack initiation of directional hydraulic fracturing controlled by dense linear multihole drilling with various parameter values. (a) Angle $\theta$ between borehole direction and $\sigma_{1}$. (b) Borehole spacing $D$. (c) Difference in principal stress $\Delta \sigma$.

boreholes gradually approaches; in the 15-10 step, the two cracks begin to connect with each other, and the pore water pressure zone gradually connects. A continuous high-porosity water pressure strip along the line of the borehole is formed.

The pore water pressure of the borehole connection during the hydraulic fracturing process is shown in Figure 10(b). It can be seen that in step 14-1, the pore water pressure between the boreholes is lower, and the pore water pressure gradient is larger. In step 15-7, the pore water pressure between the boreholes increases, and the pore water pressure gradient decreases. In step 15-10, the pore water pressure between the boreholes further increases, and the pore water pressure gradient substantially disappears. It shows that with the expansion and connection of cracks, the pore water pressure between the boreholes gradually increases, and the pore water pressure gradient gradually decreases. 

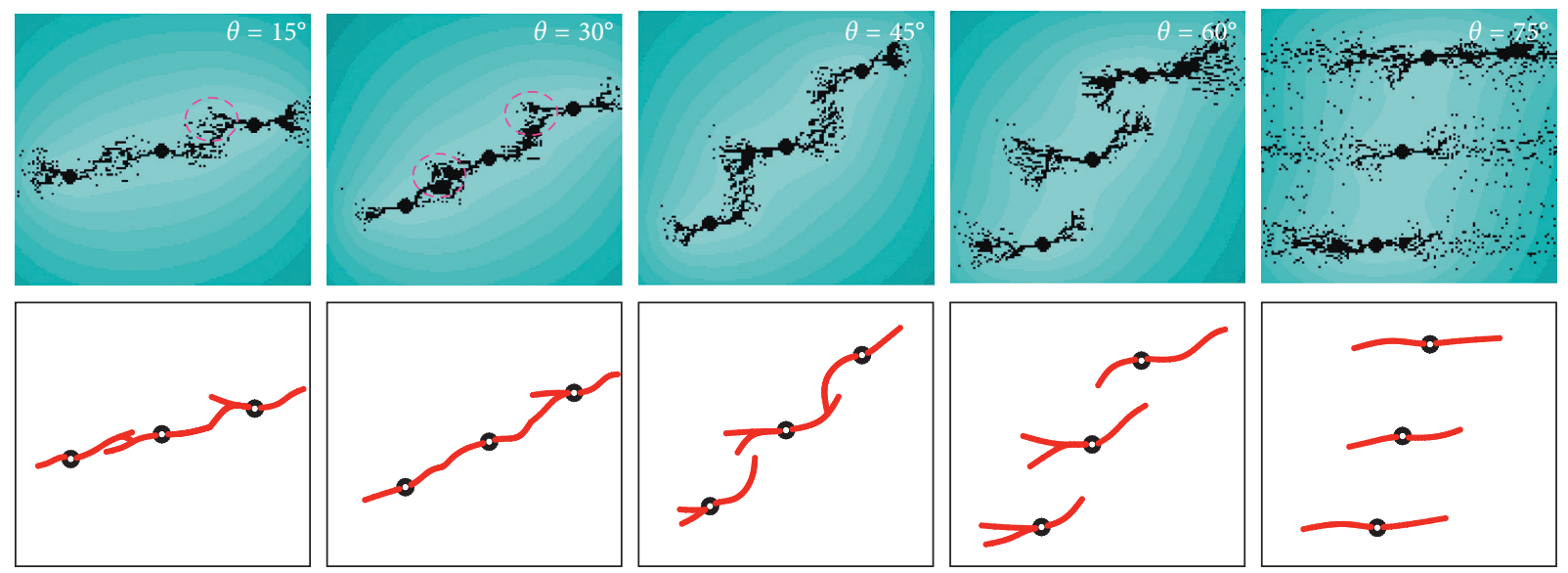

(a)
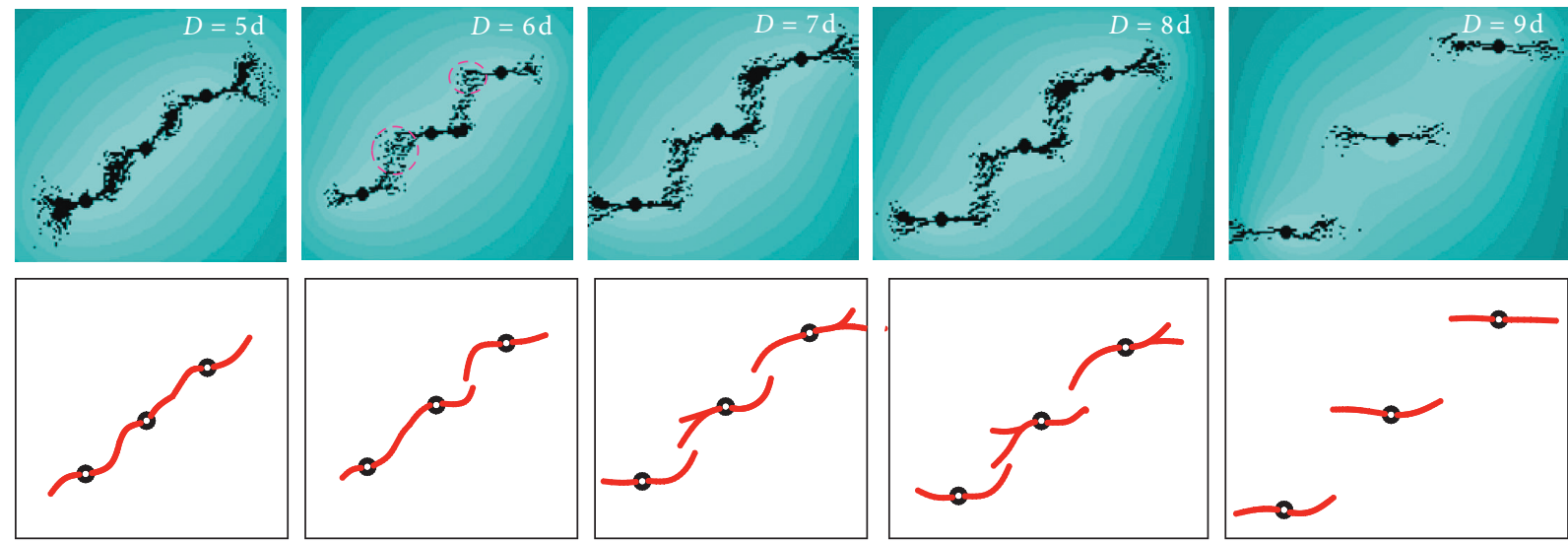

(b)
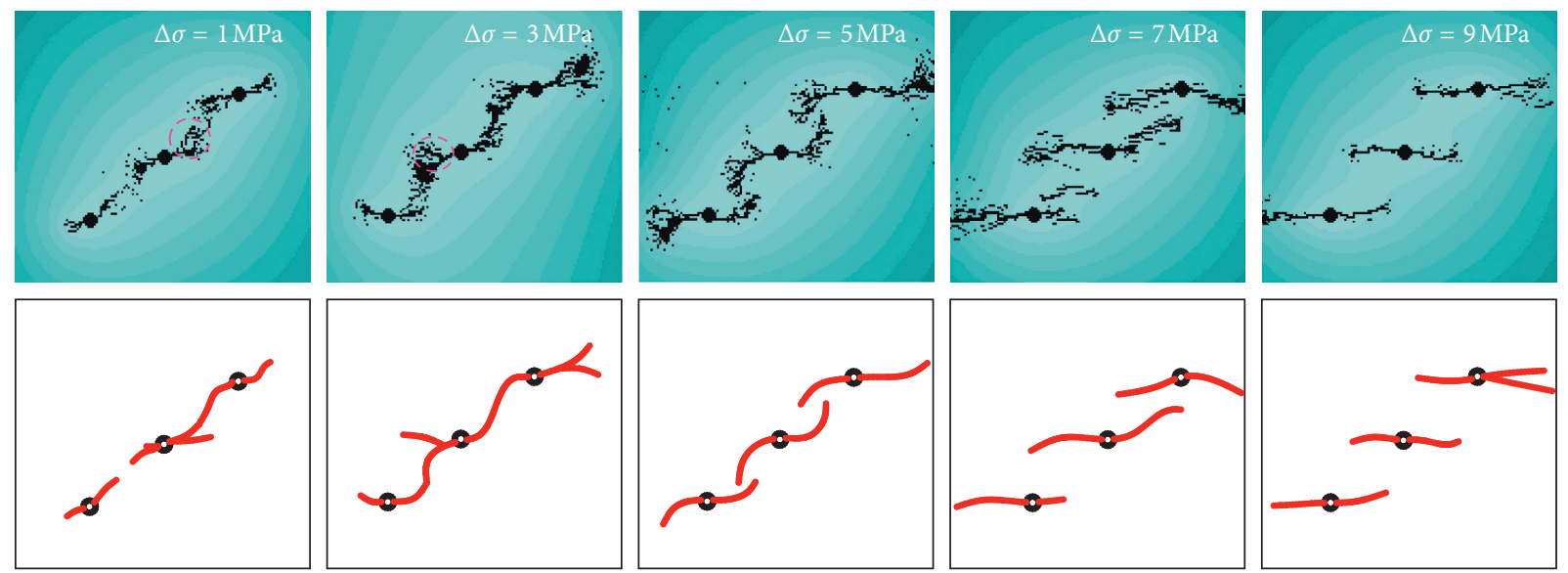

(c)

FIGURE 8: Crack propagation of directional hydraulic fracturing controlled by dense linear multihole drilling with various parameter values. (a) Angle $\theta$ between borehole direction and $\sigma_{1}$. (b) Borehole spacing $D$. (c) Difference in principal stress $\Delta \sigma$.

The acoustic emission event during the hydraulic fracturing process is shown in Figure 10(c). It can be seen that in step 14-1, a fewer number of acoustic emission events begin to appear in the borehole wall; in step 15-7, with the expansion of the crack, a large number of acoustic emission events at the tip of the crack appear; in step 15-10, a large amount of acoustic emission is generated between the two cracks and the cracks that connect with each or the reappear. It can be seen that the acoustic emission is mainly concentrated in the area between the drilled holes on both sides, so fewer acoustic emission events occur in the outer area of the drilled holes on both sides. 


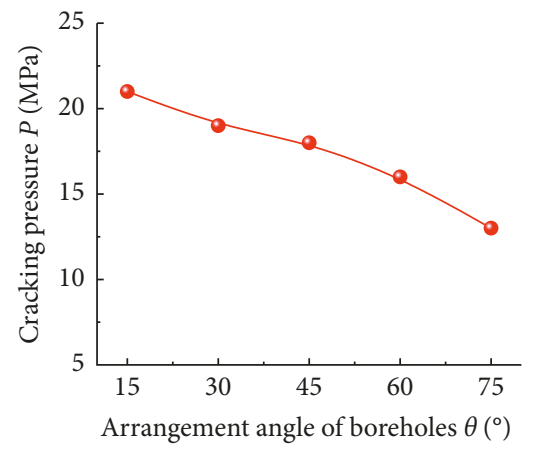

(a)

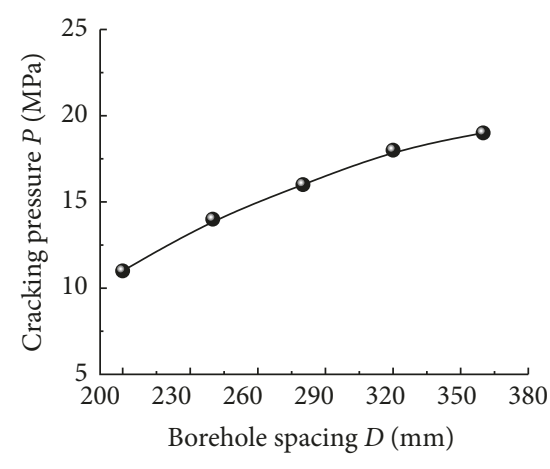

(b)

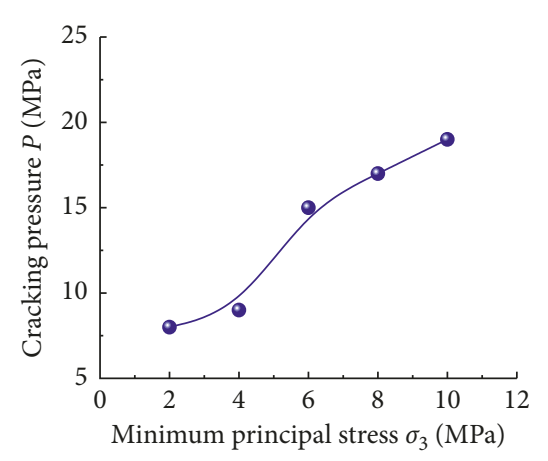

(c)

FIGURE 9: Fracture water pressure under different influencing factors. (a) Angle $\theta$ between borehole direction and $\sigma_{1}$. (b) Borehole spacing D. (c) Minimum principal stress $\sigma_{3}$.
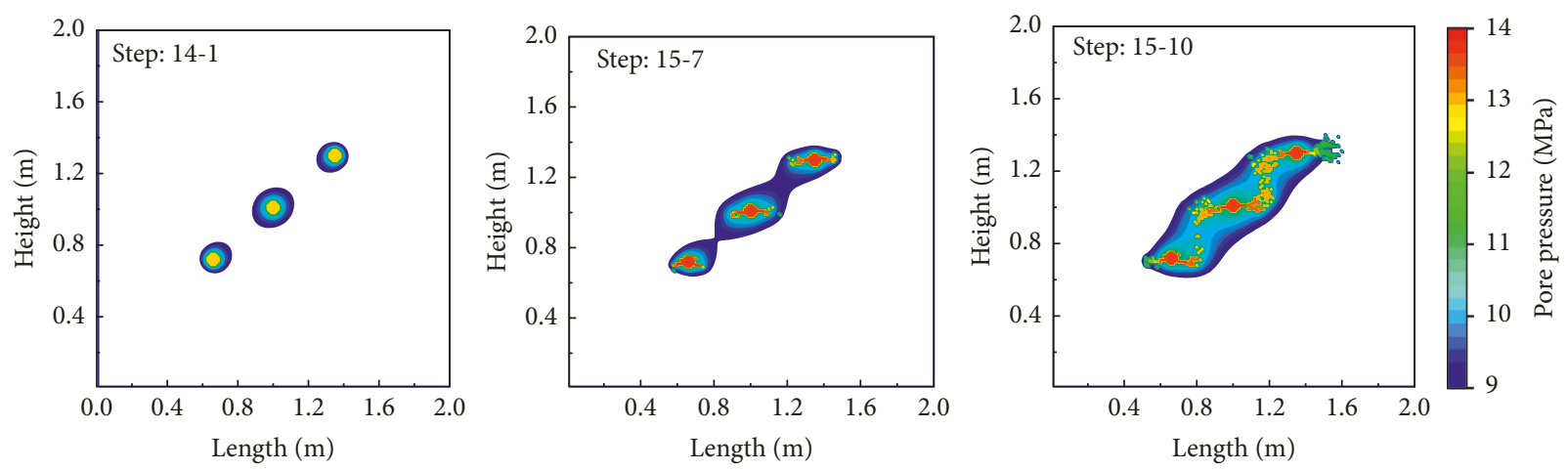

(a)

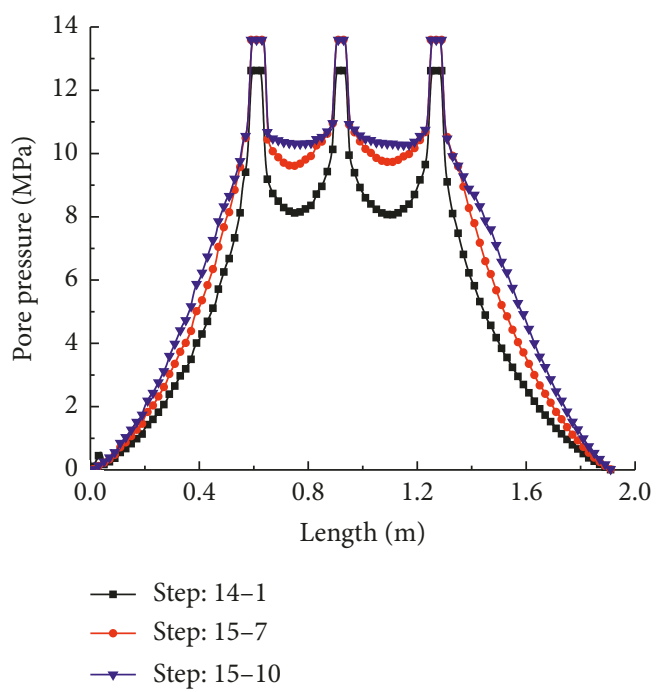

(b)
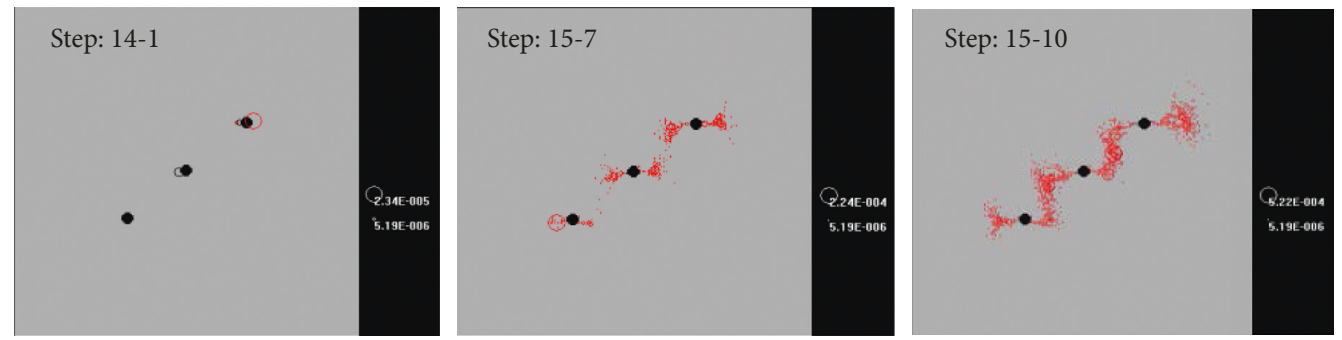

(c)

FIgURE 10: Pore water pressure and evolution of damage due to multicrack propagation. (a) Pore water pressure. (b) Pore water pressure for drilling connections. (c) Acoustic emission event. 

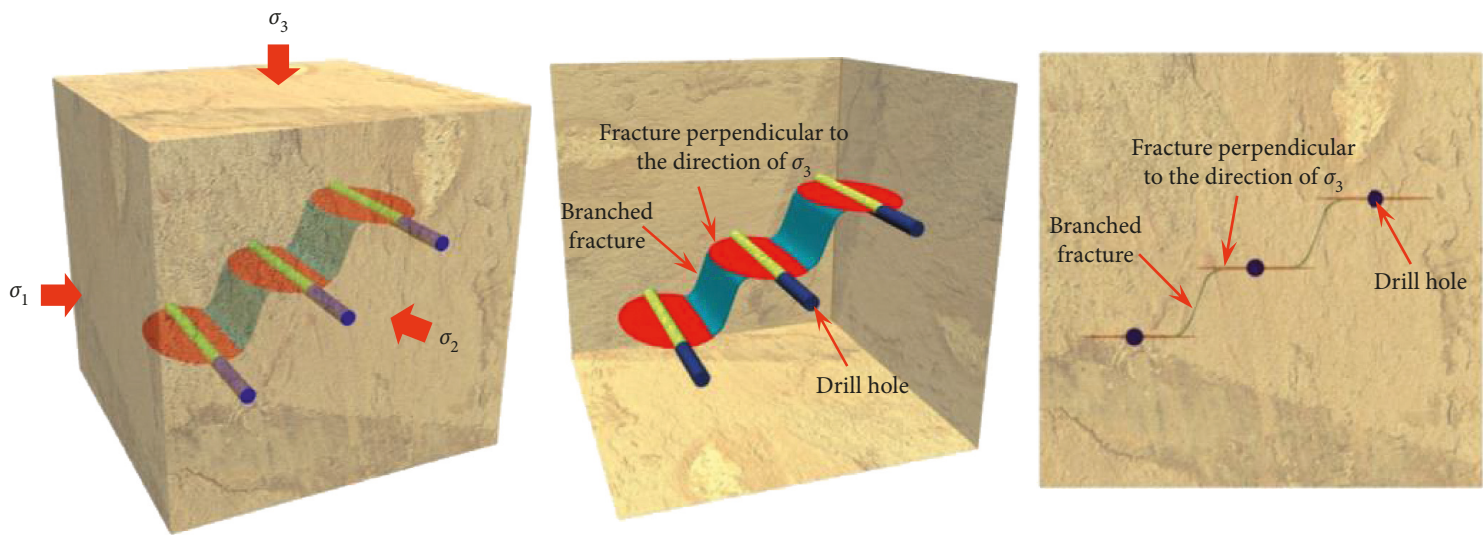

FIgURE 11: Three-dimensional configuration of hydraulic cracks.

\section{Crack Initiation and Propagation Modes for Directional Hydraulic Fracturing Controlled by Dense Linear Multihole Drilling}

Figure 11 shows the three-dimensional configuration of hydraulic cracks according to crack initiation and propagation of directional hydraulic fracturing controlled by dense linear multihole drilling. Two rupture directions with distinct advantages for crack are the direction of the borehole line and the direction perpendicular to $\sigma_{3}$, and the rupture characteristics under different conditions result from the competitive relationship between these two directions.

For small $\theta, D$, and $\Delta \sigma$, the pore pressures between boreholes become superimposed on each other, so the tensile stress is largest in the direction of the borehole line, and the test block mainly initiates and propagates in the direction of the borehole line, which results in linear cracking. Increasing $\theta, D$, and $\Delta \sigma$ weakens the superposition of pore pressure between boreholes. The cracks initiate both along the borehole line and perpendicular to $\sigma_{3}$. After crack initiation, the cracks are deflected in the direction of the borehole line: large deflections form a ladder pattern of cracks, whereas slight deflections form an S-shaped pattern of cracks. Upon further increasing $\theta, D$, and $\Delta \sigma$, hydraulic cracks initiate perpendicular to $\sigma_{3}$. Branch cracks appear upon subsequent propagation, and cracks propagate both along the borehole line and perpendicular to $\sigma_{3}$. When $\theta, D$, and $\Delta \sigma$ are very large, the pore pressures between boreholes are difficult to superimpose, and hydraulic cracks initiate and propagate only perpendicular to $\sigma_{3}$, with no branch cracks or rotational behavior.

By increasing $\theta, D$, and $\Delta \sigma$, hydraulic cracks exhibit three typical initiation behaviors in sequence: (1) initiation along the borehole line (Figure 12(a) (A)); (2) initiation both along the borehole line and perpendicular to $\sigma_{3}$ (Figure 12(a) (B)); (3) initiation perpendicular to $\sigma_{3}$ (Figure 12(a) (C)). During propagation, hydraulic cracks exhibit five typical propagation behaviors in sequence: (1) propagation along the borehole line (Figure 12(b) (A)); (2) propagation forming the ladder pattern (Figure 12(b) (B)); (3) propagation forming the S-shaped pattern (Figure 12(b) (C)); (4) propagation both along the borehole line and perpendicular to $\sigma_{3}$ (Figure 12(b) (D)); and (5) propagation perpendicular to $\sigma_{3}$ (Figure 12(b) (E)). The initiation and propagation of hydraulic cracks are affected both by the geostress field and by pore water pressure.

\section{Conclusion}

The directional propagation of hydraulic cracks in a borehole section is more evident than that outside the borehole section.

By increasing $\theta, D$, and $\Delta \sigma$, hydraulic cracks exhibit three typical initiation behaviors in sequence: (a) initiation along the borehole line; (b) initiation both along the borehole line and perpendicular to $\sigma_{3}$; and (c) initiation perpendicular to $\sigma_{3}$.

By increasing $\theta, D, \Delta \sigma$, hydraulic cracks exhibit five typical propagation behaviors in sequence: (a) propagation along the borehole line; (b) propagation forming a ladder pattern of cracks; (c) propagation forming an S-shaped pattern; (d) propagation both along the borehole line and perpendicular to $\sigma_{3}$; and (e) propagation perpendicular to $\sigma_{3}$.

The initiation and propagation of hydraulic cracks are affected by both the geostress field and the pore water pressure. With the cracking expansion of the hydraulic crack, the pore water pressure field sequentially shows the process of circularlocal contact-total connection, which gradually develops from the interval distribution to continuous high-stress strip. When multiple cracks approach each other, the pore water pressure fields at the tip of two cracks become superimposed on each other, which generates numerous microcracks between the two crack tips. This phenomenon damages the coal rock, which provides conditions for the reorientation and intersection of cracks.

Based on the crack initiation and propagation laws of directional hydraulic fracturing controlled by dense linear multihole drilling, we give the three-dimensional configuration of crack propagation by considering the effect of the pressure gradient of pore water. 


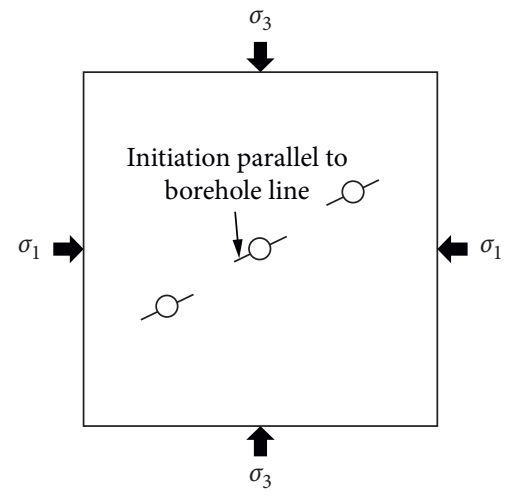

(A)

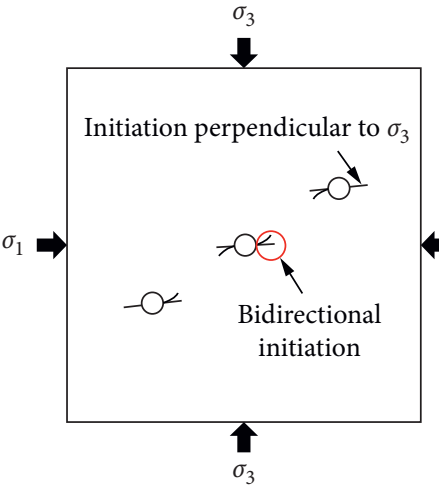

(B)

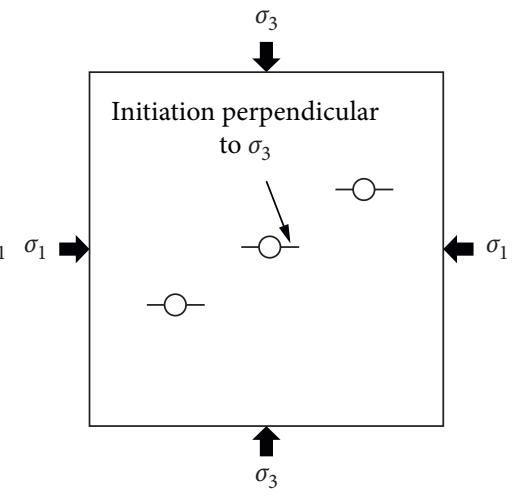

(C)

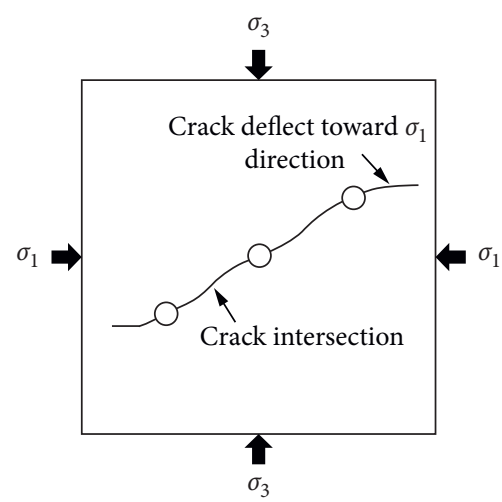

(A)

(a)

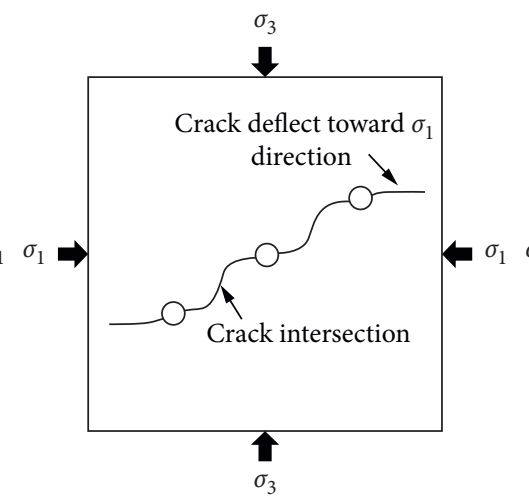

(B)

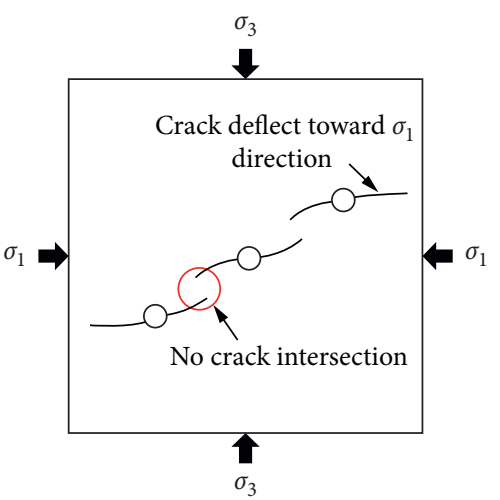

(C)

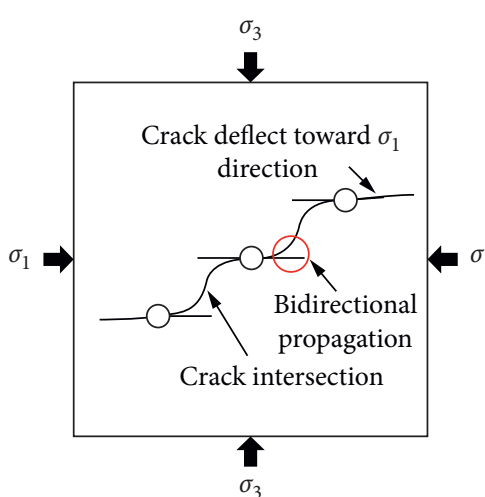

(D)

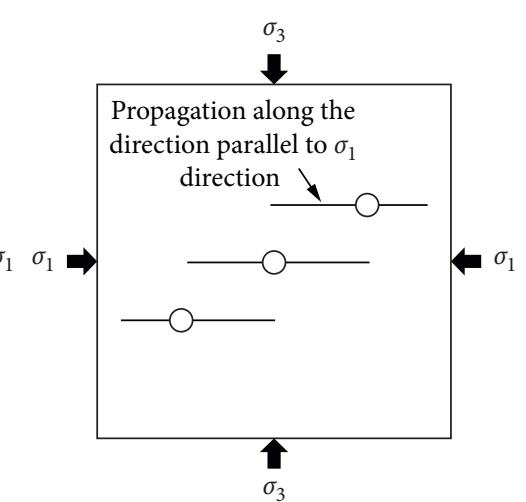

(E)

(b)

FIGURE 12: Crack initiation and propagation modes of directional hydraulic fracturing controlled by dense linear multihole drilling. (a) Three modes of crack initiation of directional hydraulic fracturing controlled by dense linear multihole drilling. (A) Initiation along the borehole line. (B) Bidirectional initiation. (C) Initiation perpendicular to $\sigma_{3}$. (b) Five modes of crack propagation of directional hydraulic fracturing controlled by dense linear multihole drilling. (A) Propagation along borehole line. (B) Propagation forming ladder pattern. (C) Propagation forming S-shaped pattern. (D) Bidirectional propagation. (E) Propagation perpendicular to $\sigma 3$.

\section{Data Availability}

The data used to support the findings of this study are available from the corresponding author upon request.

\section{Conflicts of Interest}

The authors declare that there are no conflicts of interest regarding the publication of this paper. 


\section{Acknowledgments}

This study was supported by the National Key R\&D Program of China (2018YFC0604703) and the Natural Science Foundation of Jiangsu Province (BK20161184).

\section{References}

[1] C. A. Wright and L. Weijers, "Hydraulic fracture reorientation: does it occur? Does it matter?" The Leading Edge, vol. 20, no. 10, pp. 1185-1189, 2001.

[2] C. Zhai, M. Li, C. Sun, J. Zhang, W. Yang, and Q. Li, "Guidingcontrolling technology of coal seam hydraulic fracturing fractures extension," International Journal of Mining Science and Technology, vol. 22, no. 6, pp. 831-836, 2012.

[3] O. I. Chernov, "Hydrodynamic stratification of petrologically uniform strong rocks as a means of controlling intransigent roofs," Soviet Mining Science, vol. 18, no. 2, pp. 102-107, 1982.

[4] J. Fan, L. Dou, H. He et al., "Directional hydraulic fracturing to control hard-roof rockburst in coal mines," International Journal of Mining Science and Technology, vol. 22, no. 2, pp. 177-181, 2012.

[5] Y. M. Lekontsev and P. V. Sazhin, "Directional hydraulic fracturing in difficult caving roof control and coal degassing," Journal of Mining Science, vol. 50, no. 5, pp. 914-917, 2014.

[6] S. Yan, Y. Ning, L. Kang, Y. Shi, Y. Wang, and Y. Li, "The mechanism of hydrobreakage to control hard roof and its test study," Journal of China Coal Society, vol. 25, pp. 32-35, 2000.

[7] M. Chen, H. Jiang, G. Zhang, and Y. Jin, "The experimental investigation of fracture propagation behavior and fracture geometry in hydraulic fracturing through oriented perforations," Liquid Fuels Technology, vol. 28, p. 10, 2010.

[8] G. Zhang and M. Chen, "Complex fracture shapes in hydraulic fracturing with orientated perforations," Petroleum Exploration and Development, vol. 36, pp. 103-107, 2009.

[9] Q. He, F. T. Suorineni, and J. Oh, "Review of hydraulic fracturing for preconditioning in cave mining," Rock Mechanics and Rock Engineering, vol. 49, no. 12, pp. 4893-4910, 2016.

[10] E. N. Sher and I. V. Kolykhalov, "Propagation of closely spaced hydraulic fractures," Journal of Mining Science, vol. 47, no. 6, pp. 741-750, 2011.

[11] H. He, L. Dou, J. Fan, T. Du, and X. Sun, "Deep-hole directional fracturing of thick hard roof for rockburst prevention," Tunnelling and Underground Space Technology, vol. 32, pp. 34-43, 2012.

[12] B. Huang, Y. Wang, and S. Cao, "Cavability control by hydraulic fracturing for top coal caving in hard thick coal seams," International Journal of Rock Mechanics and Mining Sciences, vol. 74, pp. 45-57, 2015.

[13] C. Song, Y. Lu, Y. Jia, and B. Xia, "Effect of coal-rock interface on hydraulic fracturing propagation," Journal of Northeastern University, vol. 35, pp. 1340-1345, 2014.

[14] B. Huang, C. Liu, J. Fu, and H. Guan, "Hydraulic fracturing after water pressure control blasting for increased fracturing," International Journal of Rock Mechanics and Mining Sciences, vol. 48, no. 6, pp. 976-983, 2011.

[15] M. He, G. Zhu, and Z. Guo, "Longwall mining "cutting cantilever beam theory" and 110 mining method in ChinaThe third mining science innovation," Journal of Rock Mechanics and Geotechnical Engineering, vol. 7, no. 5, pp. 483492, 2015.

[16] D. G. Gong, Z. Q. Qu, T. K. Guo, Y. Tian, and K. H. Tian, "Variation rules of fracture initiation pressure and fracture starting point of hydraulic fracture in radial well," Journal of Petroleum Science and Engineering, vol. 140, pp. 41-56, 2016.

[17] X.-H. Tan, J.-Y. Liu, X.-P. Li, L.-H. Zhang, and J. Cai, “A simulation method for permeability of porous media based on multiple fractal model," International Journal of Engineering Science, vol. 95, pp. 76-84, 2015.

[18] M. M. Hossain and M. K. Rahman, "Numerical simulation of complex fracture growth during tight reservoir stimulation by hydraulic fracturing," Journal of Petroleum Science and Engineering, vol. 60, no. 2, pp. 86-104, 2008.

[19] B. Xian, B. Xia, Y. Zhang, Q. Xiao, L. Cao, and Z. Chen, "Technical analysis on radical horizontal well for development of coalbed methane of low coal rank," Coal Geology \& Exploration, vol. 38, pp. 25-29, 2010.

[20] G. Wu, "Process study on radial drilling technology to exploit cbm in qinshui basin," China Coal, vol. 38, pp. 9-12, 2012.

[21] C. Wang, W. Xu, B. Peng, D. Yuan, J. Zou, and G. Wu, "Numerical simulation and application of hydraulic fracturing on directional drillings," Coal Technology, vol. 34, no. 9, pp. 160-162, 2015.

[22] R. Guo, G. Li, Z. Huang, S. Tian, X. Zhang, and W. Wu, "Theoretical and experimental study of the pulling force of jet bits in radial drilling technology," Petroleum Science, vol. 6, no. 4, pp. 395-399, 2009.

[23] A. G. Bashkirov and A. V. Vityazev, "Statistical mechanics of fragmentation processes of ice and rock bodies," Planetary and Space Science, vol. 44, no. 9, pp. 909-915, 1996.

[24] Z. Dong, S. Tang, P. G. Ranjith, and Y. Lang, "A theoretical model for hydraulic fracturing through a single radial perforation emanating from a borehole," Engineering Fracture Mechanics, vol. 196, pp. 28-42, 2018.

[25] S. Tang, Z. Dong, D. Duan, and Y. Li, "A theoretical model for hydraulic fracturing through two symmetric radial perforations emanating from A borehole," Advances in Materials Science and Engineering, vol. 2019, Article ID 6094305, 21 pages, 2019.

[26] T. Guo, B. Liu, Z. Qu, D. Gong, and L. Xin, "Study on initiation mechanisms of hydraulic fracture guided by vertical multi-radial boreholes," Rock Mechanics and Rock Engineering, vol. 50, no. 7, pp. 1767-1785, 2017.

[27] B. Xia, K. Hu, Y. Lu, Y. Liu, and C. Song, "Mechanism of crack-oriented of hydraulic crack and its technique in mine," Journal of Chongqing University, vol. 36, pp. 8-13, 2013.

[28] B. Lenoach, "The crack tip solution for hydraulic fracturing in a permeable solid," Journal of the Mechanics and Physics of Solids, vol. 43, no. 7, pp. 1025-1043, 1995.

[29] C. A. Tang, L. G. Tham, P. K. K. Lee, T. H. Yang, and L. C. Li, "Coupled analysis of flow, stress and damage (fsd) in rock failure," International Journal of Rock Mechanics and Mining Sciences, vol. 39, no. 4, pp. 477-489, 2002.

[30] T. Yang, Study on Permeability Character and Coupling Analysis of Seepage and Stress in Rock Failure Process, Northeastern University, Shenyang, China, 2002.

[31] C. Song, Y. Lu, H. Tang, and Y. Jia, "A method for hydrofracture propagation control based on non-uniform pore pressure field," Journal of Natural Gas Science and Engineering, vol. 33, pp. 287-295, 2016.

[32] Y. Cheng, Y. Lu, Z. Ge, and J. Zhong, "Influence of pore water pressure gradient on guiding hydraulic fracturing in underground coal mine," Journal of Northeastern University, vol. 38, pp. 1043-1048, 2017.

[33] X. Zhao, B. Huang, and Z. Wang, "Experimental investigation on the basic law of directional hydraulic fracturing controlled by dense linear multi-hole drilling," Rock Mechanics and Rock Engineering, vol. 51, pp. 1-16, 2018. 


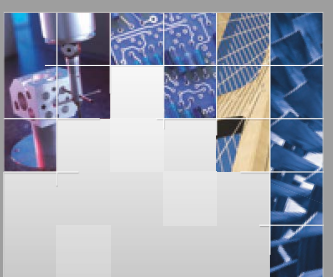

\section{Enfincering}
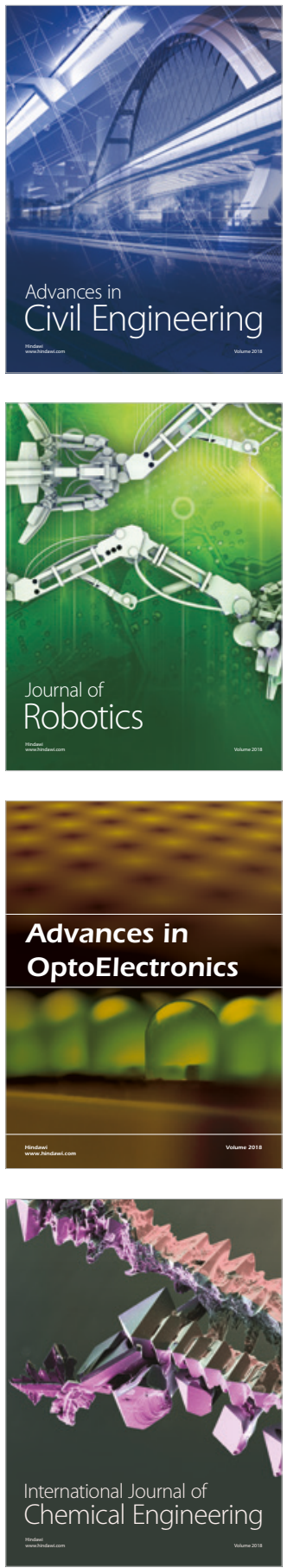

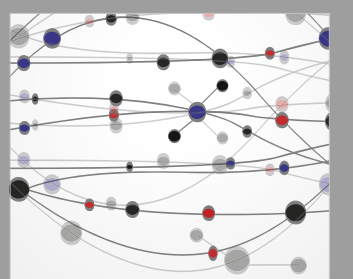

\section{Rotating \\ Machinery}

The Scientific World Journal

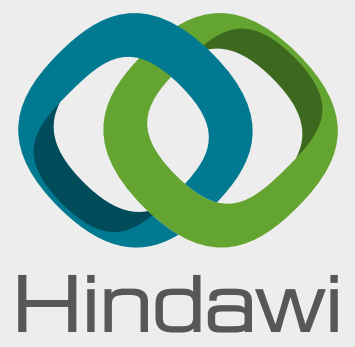

Submit your manuscripts at

www.hindawi.com
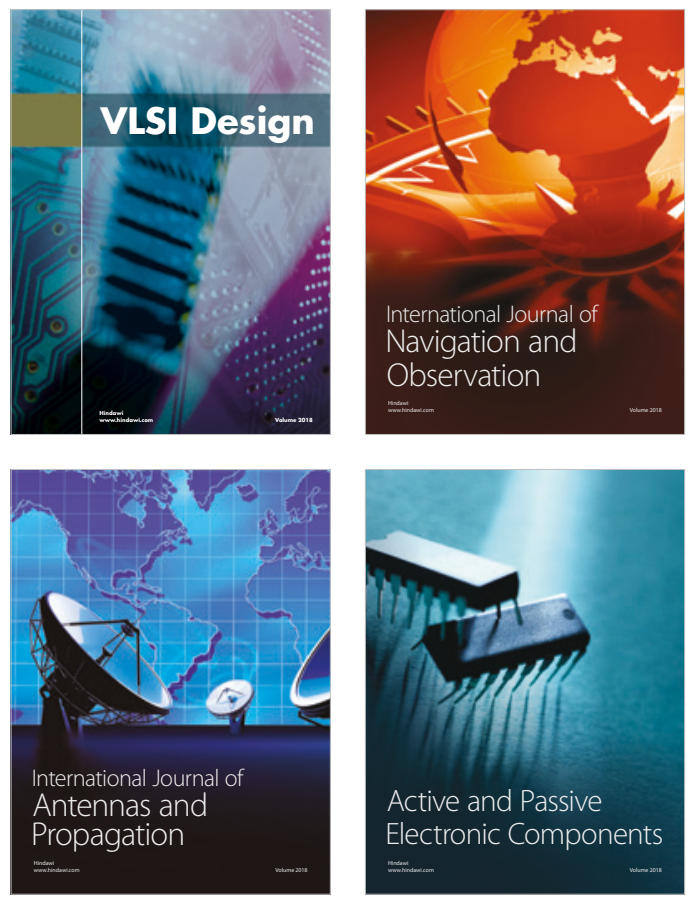
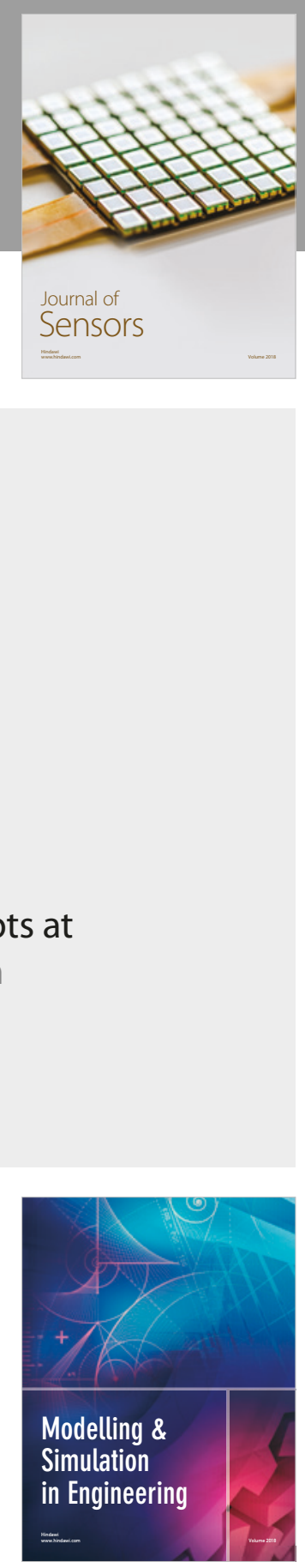

\section{Advances \\ Multimedia}
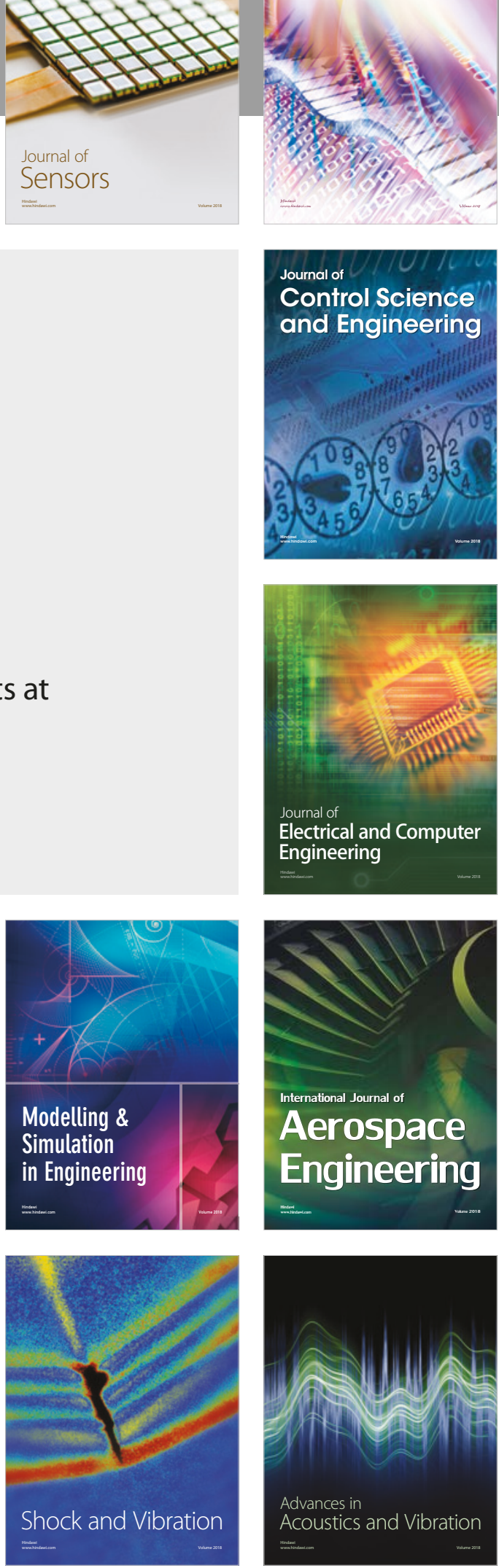